\title{
Impaired Pulmonary Arterial Vasoconstriction and Nitric Oxide-Mediated Relaxation Underlie Severe Pulmonary Hypertension in the Sugen-Hypoxia Rat Model
}

\author{
Helen Christou, Hannes Hudalla, Zoe Michael, Evgenia J. Filatava, Jun Li, Minglin Zhu, \\ Jose S. Possomato-Vieira, Carlos Dias-Junior, Stella Kourembanas, and Raouf A. Khalil \\ Department of Pediatric Newborn Medicine (H.C., H.H., Z.M., E.J.F., S.K.), and Division of Vascular and Endovascular Surgery (J. \\ L., M.Z., J.S.P.-V., C.D.-J., R.A.K.), Brigham and Women's Hospital, and Division of Newborn Medicine, Children's Hospital (H. \\ C., S.K.), Harvard Medical School, Boston, Massachusetts; and Department of Neonatology, Children's University Hospital, \\ Heidelberg, Germany (H.H.)
}

Received August 25, 2017; accepted December 4, 2017

\begin{abstract}
Pulmonary vasoreactivity could determine the responsiveness to vasodilators and, in turn, the prognosis of pulmonary hypertension $(\mathrm{PH})$. We hypothesized that pulmonary vasoreactivity is impaired, and we examined the underlying mechanisms in the Sugen-hypoxia rat model of severe PH. Male Sprague-Dawley rats were injected with Sugen $(20 \mathrm{mg} / \mathrm{kg} \mathrm{s.c.)}$ and exposed to hypoxia $\left(9 \% \mathrm{O}_{2}\right)$ for 3 weeks, followed by 4 weeks in normoxia $(\mathrm{Su} / \mathrm{Hx})$, or treated with Sugen alone $(\mathrm{Su})$ or hypoxia alone $(\mathrm{Hx})$ or neither (Nx). After hemodynamic measurements, the heart was assessed for right ventricular hypertrophy (Fulton's index); the pulmonary artery, aorta, and mesenteric arteries were isolated for vascular function studies; and contractile markers were measured in pulmonary arteries using quantitative polymerase chain reaction (PCR). Other rats were used for morphometric analysis of pulmonary vascular remodeling. Right ventricular systolic pressure and Fulton's index were higher in Su/Hx versus $\mathrm{Su}, \mathrm{Hx}$, and $\mathrm{Nx}$ rats. Pulmonary vascular remodeling was more prominent in $\mathrm{Su} / \mathrm{Hx}$ versus $\mathrm{Nx}$ rats. In pulmonary artery rings, contraction to high $\mathrm{KCl}(96 \mathrm{mM})$ was less in $\mathrm{Su} / \mathrm{Hx}$ versus $\mathrm{Nx}$ and $\mathrm{Su}$, and phenylephrine-induced contraction was reduced in
\end{abstract}

$\mathrm{Su} / \mathrm{Hx}$ versus $\mathrm{Nx}, \mathrm{Hx}$, and Su. Acetylcholine (ACh)-induced relaxation was less in $\mathrm{Su} / \mathrm{Hx}$ versus $\mathrm{Nx}$ and $\mathrm{Hx}$, suggesting reduced endothelium-dependent vasodilation. ACh relaxation was inhibited by nitric oxide synthase (NOS) and guanylate cyclase blockade in all groups, suggesting a role of the NO-cGMP pathway. Nitrate/nitrite production in response to ACh was less in $\mathrm{Su} / \mathrm{Hx}$ versus $\mathrm{Nx}$, supporting reduced endothelial NO production. Sodium nitroprusside $\left(10^{-8} \mathrm{M}\right)$ caused less relaxation in $\mathrm{Su} / \mathrm{Hx}$ versus $\mathrm{Nx}, \mathrm{Hx}$, and $\mathrm{Su}$, suggesting a decreased responsiveness of vascular smooth muscle (VSM) to vasodilators. Neither contraction nor relaxation differed in the aorta or mesenteric arteries of all groups. PCR analysis showed decreased expression of contractile markers in pulmonary artery of Su/Hx versus $\mathrm{Nx}$. The reduced responsiveness to vasoconstrictors and NO-mediated vasodilation in the pulmonary, but not systemic, vessels may be an underlying mechanism of severe $\mathrm{PH}$ in $\mathrm{Su} / \mathrm{Hx}$ rats and appears to involve attenuation of the NO relaxation pathway and a switch of pulmonary VSM cells to a synthetic less reactive phenotype.

\section{Introduction}

Pulmonary hypertension $(\mathrm{PH})$ is a heterogeneous clinical syndrome with poor prognosis. $\mathrm{PH}$ involves vasoconstriction and progressive structural remodeling of the pulmonary arterioles resulting in right ventricular hypertrophy (RVH) and failure; however, the underlying pathogenetic mechanisms of PH remain incompletely understood. Although both pulmonary vasoconstriction and obliteration of the pulmonary

This work was supported by grants from the National Institutes of Health National Heart, Lung, and Blood Institute (R01 HL-065998 to R.A.K. and R01 HL-116573 to H.C.). S.K. was supported by R01 HL055454.

https://doi.org/10.1124/jpet.117.244798. arterioles contribute to increased pulmonary vascular resistance, invasive hemodynamic studies have shown that only a small percentage of patients have a reactive component (Tonelli et al., 2010). Despite this finding, all current available treatments for $\mathrm{PH}$ act by inducing pulmonary vasodilation with a smaller effect on structural remodeling. Accumulating evidence from studies in preclinical models of $\mathrm{PH}$ and in human patients supports that a phenotypic switch of pulmonary vascular smooth muscle cells (VSMCs) from contractile to synthetic phenotype underlies, at least in part, the pathophysiology of PH (Michelakis et al., 2002; McMurtry et al., 2004, 2005; Bonnet et al., 2007; Li et al., 2009). Our previous studies have shown impaired vasoconstriction and vascular

ABBREVIATIONS: Ach, acetylcholine; ANOVA, analysis of variance; DMSO, dimethyl sulfoxide; EDRF, endothelium-derived relaxing factor; ET-1, endothelin; $\mathrm{Hx}$, hypoxia alone; L-NAME, $\mathrm{N}_{\omega}$-nitro-L-arginine methyl ester; LVSP, left ventricular systolic pressure; NO, nitric oxide; NOS, nitric oxide synthase; $\mathrm{NX}$, neither treatment; $\mathrm{ODQ}, 1 \mathrm{H}-[1,2,4]$ oxadiazolo[4,3-a]quinoxalin-1-one; $\mathrm{PCR}$, polymerase chain reaction; $\mathrm{PG} \mathrm{I}_{2}, \mathrm{prostacyclin} \mathrm{PH}$, pulmonary hypertension; Phe, phenylephrine; RVH, right ventricular hypertrophy; RVSP, right ventricular systolic pressure; SNP, sodium nitroprusside; Su, Sugen alone; VEGFR, vascular endothelial growth factor receptor; VSMC, vascular smooth muscle cell. 
relaxation in pulmonary arteries in the hypoxic and monocrotaline-treated models of $\mathrm{PH}$ and suggested a role of phenotypic switch in VSMCs in the impaired pulmonary vascular responses (Mam et al., 2010). We have also shown that induction of modest acidosis by treating the hypoxic and monocrotaline rats with ammonium chloride $\left(\mathrm{NH}_{4} \mathrm{Cl}\right)$ in vivo improves right ventricular systolic pressure and pulmonary vascular responsiveness to both vasoconstrictors and vasodilators, supporting that reversing or halting the VSMC phenotypic switch would improve pulmonary arterial function in $\mathrm{PH}$ (Christou et al., 2012). Both the hypoxic and the monocrotaline models of $\mathrm{PH}$ have limitations and may not fully recapitulate the human condition (Stenmark et al., 2009). To further advance the VSMC phenotypic switch theory as a promising therapeutic target in $\mathrm{PH}$, it is imperative to determine that such mechanisms underlie the pulmonary arterial pathology in models that more closely resemble the pathology in human $\mathrm{PH}$.

The $\mathrm{Su} / \mathrm{Hx}$ rat model of experimental $\mathrm{PH}$ was first described by Taraseviciene-Stewart and coworkers as a biologically more relevant model for human PAH. This model more closely recapitulates the human pathology than do other rodent models, partly owing to its progressive nature, the formation of plexiform lesions, and ultimate lethality (TarasevicieneStewart et al., 2001; Abe et al., 2010; de Raaf et al., 2014). Sugen 5416 (semaxanib) is an antineoplastic drug with tyrosine kinase inhibitor and vascular endothelial growth factor receptor (VEGFR)-2 inhibitor properties (O'Farrell et al., 2004). Sugen 5416 in combination with hypoxia in rats and mice sets off a cascade of events that leads to structural remodeling of the pulmonary arterioles and progressively worsening hemodynamics and plexiform lesions that are not seen in any other model of PH (Zhou et al., 2016; Aiello et al., 2017). As such, this model is a useful tool to study the underlying pathogenetic mechanisms and identify novel therapeutic targets; however, a complete understanding of the underlying pulmonary vascular dysfunction mechanisms of $\mathrm{PH}$ in this model is lacking. Understanding the vascular mechanisms involved in the $\mathrm{Su} / \mathrm{Hx}$ model of severe $\mathrm{PH}$ should help develop targeted vascular protective therapies for this life-threatening disease; however, the changes in the reactivity of the pulmonary arteries to vasoconstrictor and vasodilator stimuli and the underlying mechanisms have not been systematically studied in this model. We designed the present study to test the hypothesis that $\mathrm{Su} / \mathrm{Hx}$-induced $\mathrm{PH}$ involves specific abnormalities in the pulmonary arterial responsiveness to vasoconstrictor and vasodilator stimuli and to examine the mechanisms underlying these abnormalities. We studied the hemodynamics and vascular function in three separate vascular beds: the pulmonary artery, the aorta and mesenteric arteries, isolated from $\mathrm{Su} / \mathrm{Hx}$ rat model of severe $\mathrm{PH}$, to determine: 1) whether the responsiveness of the pulmonary artery to vasoconstrictor or vasodilator stimuli is impaired in severe $\mathrm{PH}, 2$ ) whether the impaired pulmonary arterial relaxation in severe $\mathrm{PH}$ involves the endothelium-dependent NO-cGMP pathway, and 3) whether the impaired pulmonary arterial responsiveness to vasoconstrictors and vasodilators involves extensive vascular remodeling and phenotypic switch in VSM cells.

\section{Materials and Methods}

Animals and Exposures. Eight-week-old (200-250 g) male Sprague-Dawley rats (Charles River Laboratories, Wilmington, MA) were housed in the animal facility in 12-hour light/dark cycle, at $22 \pm$ $1^{\circ} \mathrm{C}$ ambient temperature and maintained on ad libitum normal Purina Rodent Chow (Purina, St. Louis, MO) and tap water. After 2 or 3 days of acclimatization, animals were injected with $20 \mathrm{mg} / \mathrm{kg}$ of Sugen 5416 s.c. (Sigma, St. Louis, MO) or equal volume of vehicle [dimethyl sulfoxide (DMSO)] and either kept in normoxia or exposed to hypoxia at $9 \% \mathrm{O}_{2}$ inside a chamber where $\mathrm{O}_{2}$ was controlled to within a $0.2 \%$ range by an OxyCycler controller (BioSpherix, Redfield, NY) as previously described (Mam et al., 2010; Christou et al., 2012). The controller injected nitrogen into the chamber to maintain the appropriate $\mathrm{FiO}_{2}$, and ventilation was adjusted to remove $\mathrm{CO}_{2}$ so that it did not exceed $5000 \mathrm{ppm}$ $(0.5 \%)$. We observed better ventilation of the chamber with the higher flow of nitrogen needed to maintain $\mathrm{O}_{2}$ at $9 \%$ as opposed to $10 \%$ and therefore opted to use $9 \%$ for our studies. The duration of hypoxic exposure was 3 weeks, followed by normoxia for 4 weeks. Normoxic rats breathed air for 7 weeks under otherwise identical conditions. After all the measurements were taken, the animals were sacrificed 7 weeks after the start of the experiment. Thus, these treatments produced four animal groups, namely, normoxia $(\mathrm{Nx})$, sugen alone $(\mathrm{Su})$, hypoxia alone $(\mathrm{Hx})$, and Sugen + hypoxia $(\mathrm{Su} / \mathrm{Hx})($ Fig. $1 \mathrm{~A})$. All experimental procedures followed the guidelines of the American Physiologic Society and the National Institutes of Health and were approved by the Institutional Animal Care and Use Committee at the Brigham and Women Hospital.

Right and Left Ventricular Systolic Pressure Measurements. Animals were anesthetized with $3 \%$ isoflurane inhalation, intubated through a tracheostomy, and mechanically ventilated on a rodent ventilator (Harvard Apparatus, tidal volume $1 \mathrm{ml} / 100 \mathrm{~g}$ body weight, 60 breaths/min). A small transverse incision was made in the abdominal wall, and the diaphragm was exposed and opened. A 23-gauge butterfly needle with tubing attached to a pressure transducer was inserted in an open-chest approach first into the right ventricle and then into the left ventricle, and pressure measurements were recorded with PowerLab monitoring hardware and software (ADInstruments, Colorado Springs, CO). Animals with heart rates less than 300 beats per minute were considered overanesthetized and their right ventricular systolic pressure (RVSP) and left ventricular systolic pressure (LVSP) measurements were excluded. Mean RVSP and LVSP over the first 10 stable heartbeats were recorded.

Tissue Isolation. Animals were anesthetized with isoflurane; while in deep anesthesia, they were sacrificed by exsanguination and immediate harvesting of vital organs. In euthanized rats, the thoracic cavity was opened, and the heart, lung, pulmonary arteries, and thoracic aorta were rapidly excised. The abdominal cavity was then opened, and the mesentery and mesenteric arterial arcade were excised and placed in oxygenated Krebs' solution. In separate experiments, the lungs were perfused and inflated and harvested for histologic analysis.

Right Ventricular Weight and Fulton's Index. The heart was carefully dissected from surrounding tissues, and both ventricles were isolated and weighed. The right ventricular wall was carefully dissected and weighed; then the remaining left ventricular wall and ventricular septum were weighed. Fulton's index was calculated as the ratio of right ventricular weight/(left ventricular + septum weight).

Vascular Preparation. The right and left pulmonary artery, the thoracic aorta, and second-order mesenteric arteries were carefully dissected; cleaned of connective tissue under microscopic visualization; and cut into $3 \mathrm{~mm}$-wide rings. For endothelium-intact segments extreme care was taken to minimize injury to the endothelium. For endothelium-denuded segments, the endothelium was removed by scraping the vessel interior five times around the tip of the forceps (for aorta and pulmonary artery) or around thin tungsten wire (for mesenteric artery). Different segments from each vascular bed were used for different experimental protocols. The remainder of the vessels was used to measure nitrate/nitrite production.

Isometric Vascular Contraction/Relaxation. Vascular segments from the same rat were suspended between two stainless-steel 
A<smiles></smiles>

$\downarrow$ Normoxia

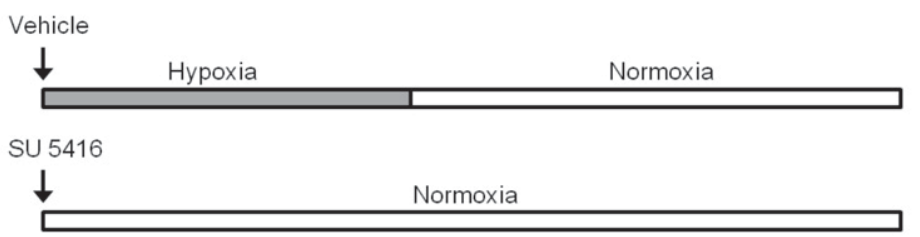

SU 5416

$\downarrow$

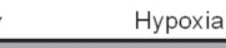

\begin{tabular}{llllllll} 
& & & & & & & 1 \\
\hline Weeks & 1 & 2 & 3 & 4 & 5 & 6 & 7
\end{tabular}

B

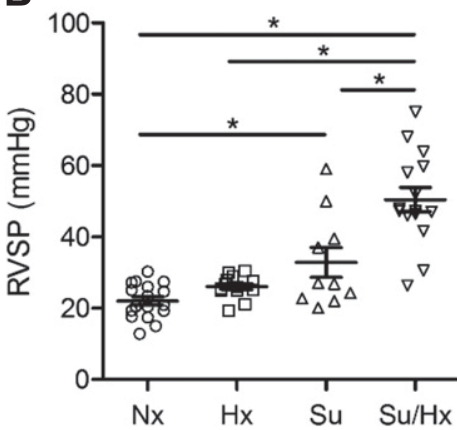

D

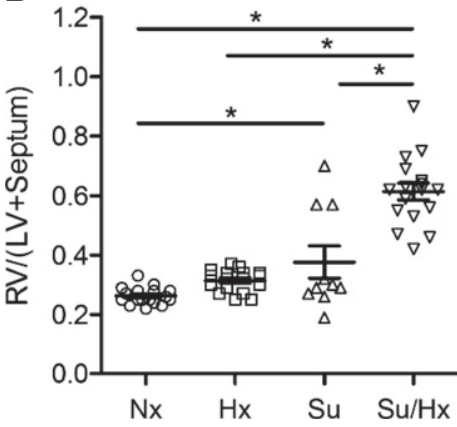

C

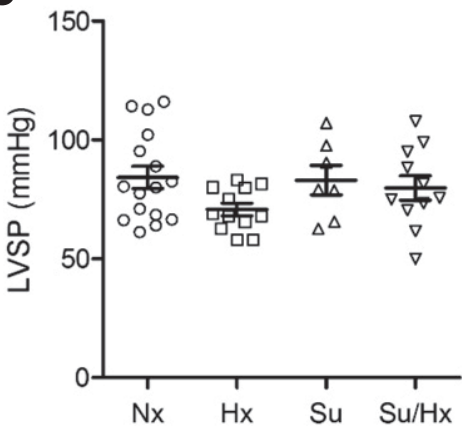

E

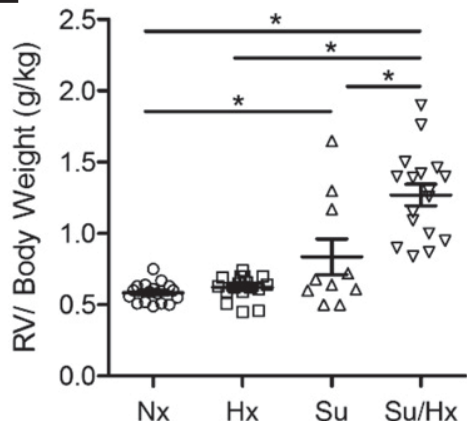

Fig. 1. Hemodynamic changes and right ventricular hypertrophy in the Sugen 5416/hypoxia $(\mathrm{Su} / \mathrm{Hx}$ ) model of $\mathrm{PH}$. Schematic representation of experimental timeline (A). Animals were injected with Sugen $(20 \mathrm{mg} / \mathrm{kg}$ s.c. $)$ or vehicle and either exposed to 3 weeks of hypoxia $\left(9 \% \mathrm{O}_{2}\right)$, followed by 4 weeks of normoxia $\left(21 \% \mathrm{O}_{2}\right)(\mathrm{Su} / \mathrm{Hx}$ and $\mathrm{Hx})$ or kept in normoxia for 7 weeks $(\mathrm{Nx}, \mathrm{Su})$. Right ventricular systolic pressure (RVSP) (B), left ventricular systolic pressures (LVSP) (C), right ventricular hypertrophy $(\mathrm{RVH})$ were assessed as the weight of the right ventricle divided by the left ventricle and septum (Fulton's index, FI); D) or as the ratio of right ventricular weight to body weight $(\mathrm{E})$. Data represent means \pm S.E.M., $n=7-17$ rats. $* P<0.05$. or tungsten wire hooks. One hook was fixed at the bottom of a tissue bath, and the other hook was connected to a Grass force transducer (FT03; Astro-Med Inc., West Warwick, RI). Large-caliber stainlesssteel wires are more suitable for larger vessels (aorta and pulmonary artery), and small-caliber tungsten wires are more suitable for smaller vessels with narrower diameter (mesenteric artery). Stainless steel cannot be stretched into very thin wires, and large-caliber tungsten wires are not malleable enough and easy to break. Extralobar firstbranch right and left pulmonary arteries, thoracic aorta, and mesenteric artery segments were stretched under 1,2 , or $0.5 \mathrm{~g}$ of resting tension, respectively, as determined by preliminary tensioncontraction curves to $\mathrm{KCl}$. We compared the pulmonary arteries to the aorta because of their close anatomic proximity. To compare the pulmonary arteries (with their role in the control of pulmonary arterial pressure) with a more relevant systemic artery (with a role in the control of the systemic arterial pressure), we also studied the mesenteric arteries. After being allowed to equilibrate for 45 minutes in a temperature-controlled, water-jacketed tissue bath, tissues were filled with $50 \mathrm{ml}$ Krebs' solution continuously bubbled with $95 \% \mathrm{O}_{2} 5 \%$ $\mathrm{CO}_{2}$ at $37^{\circ} \mathrm{C}$. Our aim was to compare vascular function under the same conditions in three different vascular beds: the pulmonary artery, aorta, and mesenteric artery. Lower oxygen concentration may affect the solution $\mathrm{pH}$ and cause acidosis, which will require further buffering to adjust the solution to a more neutral $\mathrm{pH}$. Therefore, to facilitate comparison and to minimize potential confounding factors, all vessels were treated in a similar fashion and studied in $95 \% \mathrm{O}_{2} 5 \% \mathrm{CO}_{2}$. The changes in isometric contraction were recorded on a Grass polygraph (Model 7D; Astro-Med).

After tissue equilibration, a control contraction in response to $96 \mathrm{mM} \mathrm{KCl}$ was elicited. Once maximum $\mathrm{KCl}$ contraction was reached, the tissue was rinsed with Krebs' three times, 10 minutes each time. Vascular segments were stimulated with increasing concentrations of phenylephrine (Phe, $10^{-9}-10^{-5} \mathrm{M}$ ), concentration-contraction curves were constructed, and the maximal Phe contraction and the $\mathrm{pED}_{50}$ $(-\log M)$ were calculated. In other experiments, the tissues were precontracted with submaximal Phe concentration $\left(3 \times 10^{-7}\right.$ or $\left.6 \times 10^{-7} \mathrm{M}\right)$, increasing concentrations $\left(10^{-9}-10^{-5} \mathrm{M}\right)$ of acetylcholine (ACh) were added, and the percentage of relaxation of Phe contraction was measured. Parallel contraction and relaxation experiments were performed in endotheliumintact vascular rings pretreated with the NOS inhibitor $\mathrm{N}^{\omega}$-nitro-L-arginine 
TABLE 1

Primers for genes in quantitative real-time PCR

Definition of genes: a) Contractile markers: Acta2 (smooth muscle- $\alpha 2$ actin), Cnn1 (calponin 1), Gapdh (glyceraldehyde-3-phosphate dehydrogenase), Myh11 (myosin heavy-chain 11), Smtn (smoothelin), Tagln (transgelin, also known as SM22 $\alpha$ ); (b) Synthetic marker: Rbp1 (retinol-binding protein 1); (c) Housekeeping: Nup133 (nucleoporin 133).

\begin{tabular}{|c|c|c|c|c|}
\hline Gene & Species & Accession No. & Forward Primer & Reverse Primer \\
\hline Acta2 & Rat & NM_031004.2 & 5'-CTGGACGTACAACTGGTATTG-3' & 5'-ATGAGGTAGTCGGTGAGAT-3' \\
\hline Cnn1 & Rat & NM_031747.1 & 5'-CCAGCATGGCAAAGACAA-3' & 5'-CTGTAGGCCAATGATGTTCC-3' \\
\hline Gapdh & Rat & NM_017008.4 & 5'-GACATGCCGCCTGGAGAAAC-3' & 5'-AGCCCAGGATGCCCTTTAGT-3' \\
\hline Myh11 & Rat & NM_001170600.1 & 5'-GCTACAAGATCGTGAAGACC-3' & 5'-GTGATGCTGCTGTCTTTCT-3' \\
\hline Nup133 & Rat & XM_008772670.2 & 5'-GTCTTCGATACACAAGGAGAC-3' & 5'-CTTCTGCTAACAGGGACATAC-3' \\
\hline$R b p 1$ & Rat & NM_012733.4 & 5'-TTCACCTGGAGATGAGAGC-3' & 5'-TCCTCGAGACCAAGGTTATC-3' \\
\hline Smtn & Rat & NM_001013049.2 & 5'-GAGAACTGGCTACACTCTCA-3' & 5'-AGTGTGGTCAACTCCTCTAC-3' \\
\hline Tagln & Rat & NM_031549.2 & 5'-TTATGAAGAAAGCCCAGGAG-3' & 5'-CTCTGTTGCTGCCCATTT-3' \\
\hline
\end{tabular}

methyl ester (L-NAME, $3 \times 10^{-4} \mathrm{M}$ ) or the guanylate cyclase inhibitor $1 \mathrm{H}$ $[1,2,4]$ oxadiazolo[4,3-a]quinoxalin-1-one (ODQ, $\left.10^{-5} \mathrm{M}\right)$ for 15 minutes. NO diffuses into VSM, where it activates guanylate cyclase, increases cGMP, and promotes relaxation. L-NAME is a competitive substrate that competes with L-arginine for binding with NOS. Because the endogenous concentration of L-arginine is high, very high concentrations of L-NAME $\left(3 \times 10^{-4} \mathrm{M}\right)$ are needed to block NOS and the NO-cGMP pathway. In contrast, ODQ directly inhibits guanylate cyclase at much lower concentrations $\left(10^{-5} \mathrm{M}\right)$ and could be more efficient in blocking the NO-cGMP pathway. Phe contraction and ACh relaxation were also measured in endotheliumdenuded vessels. The endothelium was removed from blood vessels of the different animal groups using the same experimental protocol. The endothelium was removed by rubbing the vessel interior five times around the tip of sharp forceps. Complete removal of the endothelium was verified by the absence of ACh-induced relaxation. Extreme care was taken to avoid damage to the underlying smooth muscle layer. Any endothelium-denuded vessels that showed more than $30 \%$ reduction in contraction to $\mathrm{Phe}$ or $\mathrm{KCl}$ compared with that in control endothelium-intact vessels were removed from the study. In other experiments, the relaxation to increasing concentrations $\left(10^{-9}-10^{-5} \mathrm{M}\right)$ of the exogenous NO donor sodium nitroprusside (SNP) was measured in vascular rings precontracted with Phe to test the ability of vascular smooth muscle to respond to vasodilators, Individual ACh and SNP concentration-relaxation curves were further analyzed using nonlinear regression, sigmoidal dose-response curves were fitted using the least-squares method, and $\mathrm{ACh}$ and $\mathrm{SNP} \mathrm{pED}_{50}$ were calculated.

Nitrate/Nitrite (NOx) Production. Endothelium-intact aortic, pulmonary artery or mesenteric arterial segments were incubated in normal Krebs'solution for 30 minutes to measure basal NO production, then stimulated with $\mathrm{ACh}\left(10^{-8}-10^{-5} \mathrm{M}\right)$ for 30 minutes, and the incubation solution was assayed for the stable end product of $\mathrm{NO}$, $\mathrm{NO}_{2}^{-}$using Griess reagent (Promega, Madison, WI) (Crews et al., 2000; Mazzuca et al., 2014).

Lung Histology and Morphometric Analysis. In a subset of experimental animals, the lungs were perfused and inflated with cold $4 \%$ paraformaldehyde, excised, and fixed in $4 \%$ paraformaldehyde overnight at $4^{\circ} \mathrm{C}$, followed by paraffin embedding. Lung sections $(6 \mu \mathrm{m})$ were stained with $\mathrm{H} \& \mathrm{E}$ and examined by light microscopy by two independent investigators (E.J.F. and H.C.) in a blinded fashion. Images of the arterioles were captured by using a microscope digital camera system (Nikon, Tokyo, Japan) and analyzed using an image analysis program (ImageJ Software, National Institutes of Health). Arterioles of comparable size (50-100 $\mu \mathrm{m}$ diameter) from the lungs of five different rats from each experimental group were evaluated. The percentage of wall thickness was determined by dividing the area occupied by the vessel wall by the total cross-sectional area of the arteriole, as previously reported (Christou et al., 2000). This method accounts for uneven vessel-wall thickness and areas that have obliquely sectioned pulmonary arterioles.

Gene Expression Analysis. In a subset of experimental animals, pulmonary arteries were harvested for RNA isolation. The right and left pulmonary arteries were carefully dissected as distally as possible and cleaned of connective tissue. The pulmonary trunk was not used for gene-expression analysis. RNA was isolated using TRIzol reagent (Invitrogen Life Technologies, Carlsbad, CA) and quantified using a NanoDrop 2000c spectrophotometer (NanoDrop Technologies, Wilmington, DE). Samples were treated with DNAse I (Sigma) to digest genomic DNA, and poly $(\mathrm{A})^{+}$mRNA was transcribed to complementary DNA (cDNA) using SuperScript III (Invitrogen Life Technologies). Relative mRNA transcript levels were analyzed with a StepOnePlus reverse transcription polymerase chain reaction (PCR) cycler (Applied Biosystems, Foster City, CA) using iTaq Universal SYBR Green Supermix (Bio-Rad, Hercules, CA). Primers were designed across exon-exon junctions and specific for all transcript variants, using where possible nBLAST (National Center for Biotechnology Information) and PrimerQuest Tool (Integrated DNA Technologies, Coralville, IA) (Table 1). Expression was analyzed using the $\Delta \Delta \mathrm{Ct}$ method. $\mathrm{Ct}$ values of target genes were normalized to the mean expression of the reference genes Nup133 (nucleoporin 133) and Gapdh using the equation $\Delta \mathrm{Ct}=\mathrm{Ct}_{\text {target }}-\left(\left(\mathrm{Ct}_{\mathrm{Nup} 133}+\mathrm{Ct}_{\mathrm{GAPDH}}\right) / 2\right)$. Data were expressed as relative mRNA expression $\left(2^{-\Delta \Delta \mathrm{Ct}}\right)$.

Solutions and Drugs. Krebs' solution contained (in millimolars) $\mathrm{NaCl} 120, \mathrm{KCl} 5.9, \mathrm{NaHCO}_{3} 25, \mathrm{NaH}_{2} \mathrm{PO}_{4} 1.2$, dextrose 11.5, $\mathrm{CaCl}_{2}$ $2.5, \mathrm{MgCl}_{2} 1.2$, at $\mathrm{pH} 7.4$ and bubbled with $95 \% \mathrm{O}_{2}$ and $5 \% \mathrm{CO}_{2}$. High $96 \mathrm{mM} \mathrm{KCl}$ solution was prepared as Krebs' solution with equimolar substitution of $\mathrm{NaCl}$ with KCl. Stock solutions of Phe, ACh, L-NAME, and SNP $\left(10^{-1} \mathrm{M}\right.$; Sigma) were prepared in distilled water. Stock solution of ODQ $\left(10^{-1} \mathrm{M}\right)$ was prepared in DMSO. A final concentration of DMSO in experimental solution was $<0.1 \%$. All other chemicals were of reagent grade or better.

Statistical Analysis. Data from different groups were analyzed by analysis of variance (ANOVA) and presented as means \pm S.E.M., with $n$ representing the number of rats per group. Hemodynamics, tissue histology, and quantitative morphometry data were analyzed with ANOVA and Tukey's post hoc analysis. For vascular reactivity experiments, individual concentration-contraction or concentrationrelaxation curves were constructed, sigmoidal curves were fitted to the data using the least-squares method, and the $\mathrm{pEC}_{50}$ values $(-\log$ $\mathrm{EC}_{50}$, drug concentration evoking half-maximal response) were measured using Prism (v.5.01; GraphPad Software, San Diego, CA). Data were first analyzed using ANOVA with multiple classification criteria [rat group ( $\mathrm{Nx}$ vs. $\mathrm{Su}, \mathrm{Hx}$, and $\mathrm{Su} / \mathrm{Hx}$ ), the condition of vascular endothelium (denuded vs. intact), vessel treatment (treated with L-NAME or ODQ vs. nontreated control tissues)]. When a statistical difference was observed, the data were further analyzed using Bonferroni's post hoc test for multiple comparisons. Student's unpaired $t$ test and Mann-Whitney test for nonparametric analyses were used for comparison of two means. Differences were considered statistically significant if $P<0.05$.

\section{Results}

Hemodynamic Measurements. Hemodynamic measurements in the $\mathrm{Su} / \mathrm{Hx}$ animals revealed significantly increased RVSP at the 7-week time point compared with Nx and 


\section{$\mathrm{KCl}-$ Induced Contraction}

\section{Pulmonary Artery}

\section{+Endo}

A

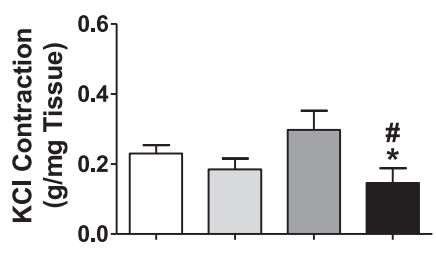

\section{-Endo}

D

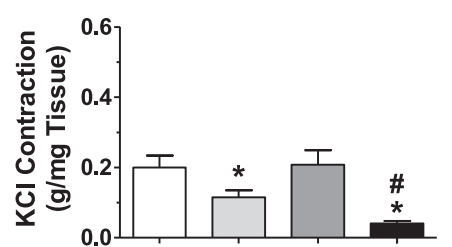

B

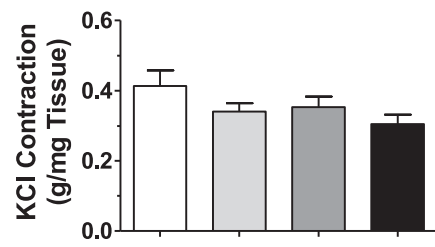

$\mathbf{E}$

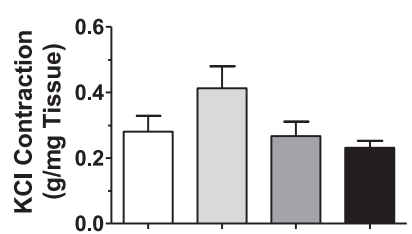

Mesenteric Artery

C
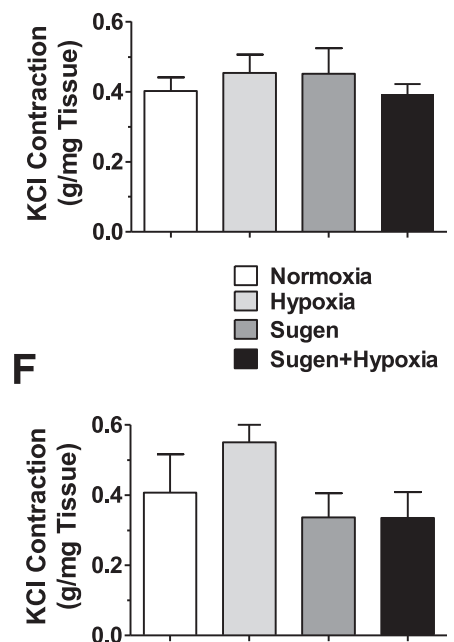

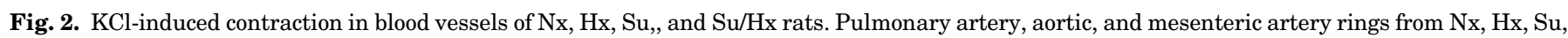

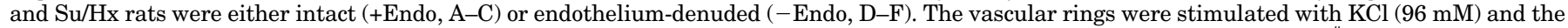
contraction in gram per milligram of tissue weight was recorded. Data represent means \pm S.E.M., $n=7-11$. ${ }^{*} P<0.05$ vs. Nx. ${ }^{\sharp} P<0.05$ vs. Su.

Hx animals (Fig. 1B). Since prior publications demonstrated that some animals develop PH after Su injection alone (without hypoxia), we included this experimental group on our study design and found that $\mathrm{Su}$ animals had an intermediate phenotype with significantly higher RVSP compared with Nx animals; however, RVSP was significantly higher in the $\mathrm{Su} / \mathrm{Hx}$ compared with the $\mathrm{Su}$ alone group. In contrast, LVSP, an indicator of the blood pressure in the systemic circulation, did not differ significantly among the different experimental groups (Fig. 1C).

The Fulton index and RV/body weight ratio, indicators of right ventricular hypertrophy, were significantly higher in $\mathrm{Su} / \mathrm{Hx}$ compared with $\mathrm{Nx}$ and $\mathrm{Hx}$ animals (Fig. 1, D and E). The Su alone animals had significantly higher Fulton's index and RV/body weight ratio than Nx animals; however, Fulton's index and the RV/body weight were significantly higher in the $\mathrm{Su} / \mathrm{Hx}$ animals compared with $\mathrm{Su}$-alone group.

Vascular Function Studies. In endothelium-intact pulmonary artery rings of control $\mathrm{Nx}$ rats, membrane depolarization by $96 \mathrm{mM} \mathrm{KCl}$ caused significant contraction. The $\mathrm{KCl}$-induced contraction was not different in pulmonary arteries of $\mathrm{Hx}$ rats, slightly increased in $\mathrm{Su}$ rats, and significantly reduced in $\mathrm{Su} / \mathrm{Hx}$ rats (Fig. 2A). In contrast, KCl-induced contraction was not significantly different in the aorta or mesenteric arteries of the different groups of rats (Fig. $2, \mathrm{~B}$ and $\mathrm{C}$ ). To test whether the reduction in pulmonary artery contraction in the $\mathrm{Su} / \mathrm{Hx}$ group is due to the release of endothelium-derived vasodilators, we examined the $\mathrm{KCl}$ response in endothelium denuded pulmonary artery. Similar to the observation in endothelium-intact pulmonary arteries, $\mathrm{KCl}$ contraction remained markedly reduced in endotheliumdenuded vessels of $\mathrm{Su} / \mathrm{Hx}$ rats compared with the $\mathrm{Nx}$ and $\mathrm{Su}$ groups (Fig. 2D), suggesting that the reduction in contraction is endothelium-independent and involves reduction in the mechanisms of VSMC contraction. Interestingly, $\mathrm{KCl}$ contraction was also significantly decreased in endothelium-denuded vessels of the $\mathrm{Hx}$ rats compared with $\mathrm{Nx}$ controls (Fig. 2D). Previous studies have shown enhanced pressor response to endothelin-1 in Hx rats (Adnot et al., 1991). It is likely that during $\mathrm{Hx}$ there is increased release of endothelium-derived contracting factors such as endothelin-1 and that the contribution of these endothelium-derived contracting factors is abolished in endothelium-denuded vessels, resulting in a reduced contractile response. In contrast, $\mathrm{KCl}$ contraction was not different in the endothelium-denuded aorta or mesenteric artery of the different groups (Fig. 2, E and F).

In pulmonary artery rings of $\mathrm{Nx}$ rats, the $\alpha$-adrenergic agonist phenylephrine (Phe) caused concentration-dependent contraction that reached a maximum at $10^{-5} \mathrm{M}$ concentration (Fig. 3A). The Phe-induced contraction of pulmonary artery in grams per milligrams was not different in $\mathrm{Hx}$ rats, slightly enhanced in Su-alone rats, but significantly reduced in $\mathrm{Su} / \mathrm{Hx}$ compared with $\mathrm{Nx}$ and $\mathrm{Su}$ rats (Fig. 3A). In contrast, Phe contraction in grams per milligrams did not differ in the aorta or mesenteric artery of the different groups (Fig. 3, B and C). When Phe contraction was presented as a percentage of max, and the $\mathrm{ED}_{50}$ was calculated, Phe appeared to be equally potent in the pulmonary arteries of $\mathrm{Nx}, \mathrm{Hx}$, and $\mathrm{Su}$ rats, but the Phe concentration-response curve was shifted to the right, suggesting lower Phe potency in $\mathrm{Su} / \mathrm{Hx}$ compared $\mathrm{Nx}, \mathrm{Hx}$, and $\mathrm{Su}$ rats (Fig. 3D). In contrast, in the aorta and mesenteric arteries, the Phe-induced concentration-response curves and ED50 did not appear to be different among the different groups (Fig. 3, E and F).

Because in different vessels, the Phe response varied from the same group, we also presented Phe contraction as a percentage of control KCL contraction in the same vessel. Phe response as \% of control $\mathrm{KCl}$ contraction was reduced in 


\section{Phe-Induced Contraction}
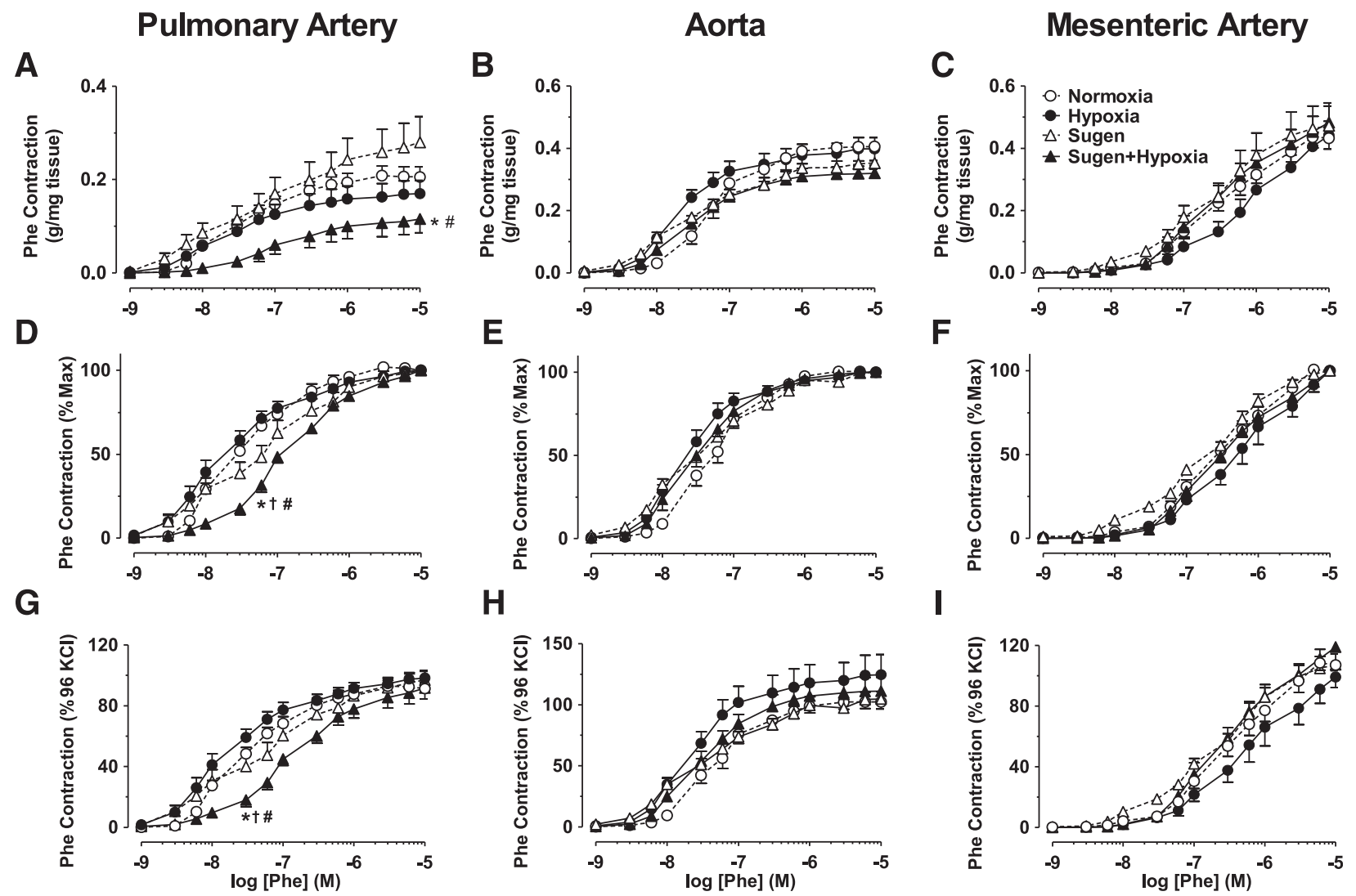

Fig. 3. Phe-induced contraction in blood vessels of $\mathrm{Nx}, \mathrm{Hx}, \mathrm{Su}$, and $\mathrm{Su} / \mathrm{Hx}$ rats. Pulmonary artery, aortic, and mesenteric artery rings from $\mathrm{Nx}$, $\mathrm{Hx}$, $\mathrm{Su}$, and $\mathrm{Su} / \mathrm{Hx}$ rats were stimulated with increasing concentrations of Phe $\left(10^{-9}-10^{-5} \mathrm{M}\right)$. The contractile response was measured and presented in gram per milligram tissue (A-C), as the percentage of maximum Phe contraction (D-F) or as the percentage of KCl contraction (G-I). Data represent means \pm S.E.M., $n=7-11 .{ }^{*} P<0.05$ vs. Nx. ${ }^{\dagger} P<0.05$ vs. Hx. ${ }^{\#} P<0.05$ vs. Su.

pulmonary artery of $\mathrm{Su} / \mathrm{Hx}$ rats compared with $\mathrm{Nx}, \mathrm{Hx}$, and $\mathrm{Su}$ rats (Fig. 3G). In contrast, the Phe contraction as the percentage of control $\mathrm{KCl}$ contraction was not significantly different in the aorta or mesenteric artery of the different groups (Fig. 3, $\mathrm{H}$ and I).

We tested the role of the endothelium in the reduced Phe contraction in the $\mathrm{Su} / \mathrm{Hx}$ rats. Pretreatment of pulmonary artery segments with the NOS inhibitor L-NAME $\left(3 \times 10^{-4} \mathrm{M}\right)$ or the guanylate cyclase inhibitor ODQ for 15 minutes or endothelium removal showed a small but not significant change in Phe contraction in $\mathrm{Nx}, \mathrm{Hx}, \mathrm{Su}$, or $\mathrm{Su} / \mathrm{Hx}$ rats (Fig. 4, A-D). When the Phe response was presented as the percentage of the maximum contraction, treatment with L-NAME or ODQ did not significantly change the Phe response in $\mathrm{Nx}, \mathrm{Hx}$, or $\mathrm{Su} / \mathrm{Hx}$ rats, whereas $\mathrm{ODQ}$ significantly enhanced the Phe response in Su rats (Fig. 4, E-H). Assuming that $\mathrm{KCl}$ contraction is due mainly to $\mathrm{Ca}^{2+}$ entry into vascular smooth muscle, then any enhancement of Phe contraction relative to $\mathrm{KCl}$ contraction would suggest possible activation of $\mathrm{Ca}^{2+}$ sensitization pathways, such as PKC or Rho kinase (Ringvold and Khalil, 2017). L-NAME and ODQ slightly but significantly enhanced Phe contraction relative to $\mathrm{KCl}$ in $\mathrm{Nx}$, but not Hx rats (Fig. 4, I and J). ODQ caused marked enhancement of Phe contraction relative to $\mathrm{KCl}$ in $\mathrm{Su}$ and $\mathrm{Su} / \mathrm{Hx}$ rats (Fig. 4, $\mathrm{K}$ and $\mathrm{L}$ ). The greater effects of ODQ versus L-NAME in enhancing Phe contraction could be related to its direct inhibition of guanylate cyclase and greater efficiency in blocking the NO-cGMP pathway.

Acetylcholine (ACh) caused concentration-dependent relaxation in Phe precontracted pulmonary artery rings of Nx rats that reached a maximum at $10^{-5} \mathrm{M}$ concentration. AChinduced pulmonary artery relaxation was not different in $\mathrm{Hx}$ rats, partially reduced in Su rats, and significantly reduced in $\mathrm{Su} / \mathrm{Hx}$ compared with $\mathrm{Nx}$ and $\mathrm{Hx}$ rats (Fig. 5A), suggesting either reduced production of, or decreased responsiveness to, endothelium-derived vasodilators, such as NO in the setting of experimental $\mathrm{PH}$. In comparison, ACh relaxation was not significantly different in Phe precontracted aorta and mesenteric artery rings of the different groups of rats (Fig. 5, B and C).

In the pulmonary artery of $\mathrm{Nx}, \mathrm{Su}$, and $\mathrm{Hx}$, the NOS inhibitor L-NAME and the guanylate cyclase inhibitor ODQ or endothelium-removal abolished ACh-induced relaxation, suggesting the involvement of endothelium-dependent NO-cGMP pathway (Fig. 6, A-C). Pretreatment with L-NAME or ODQ or endothelium-removal also abolished the small ACh-induced relaxation in pulmonary artery of $\mathrm{Su} / \mathrm{Hx}$ rats (Fig. 6D), suggesting that the vasorelaxation response to ACh in experimental PH is mediated by the NO-cGMP pathway.

In endothelium intact pulmonary artery segments, ACh caused concentration-dependent increases in nitrate-nitrite production that were reduced in $\mathrm{Hx}, \mathrm{Su}$, and $\mathrm{Su} / \mathrm{Hx}$ rats 


\section{Effect of Endothelium Blockade or Removal on Phe Contraction of Pulmonary Artery}

A

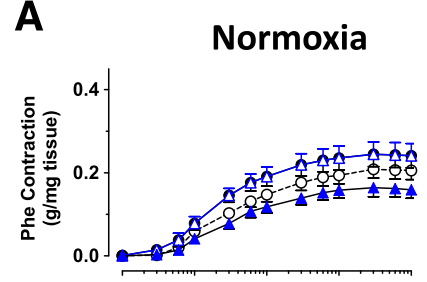

E
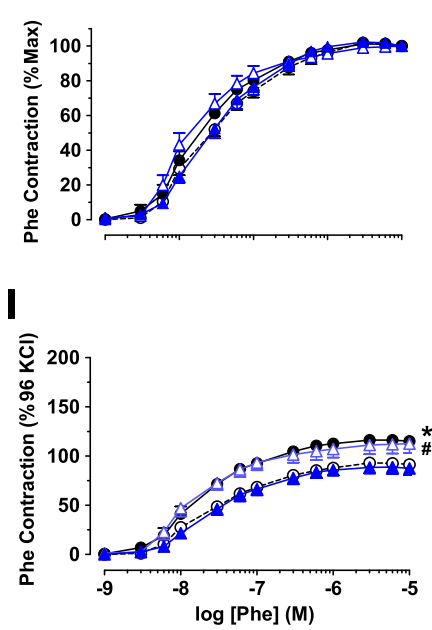

B

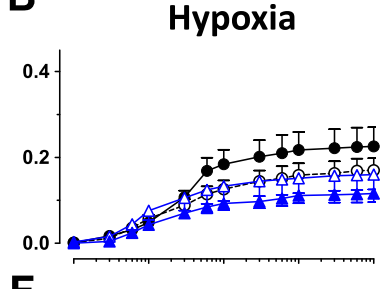

$\mathbf{F}$
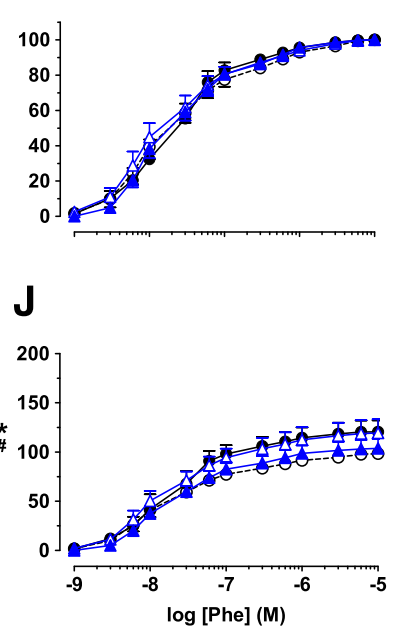

C

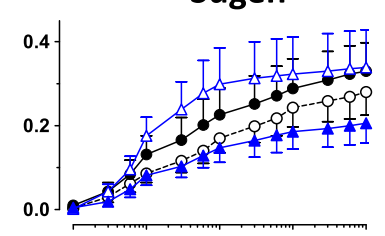

G

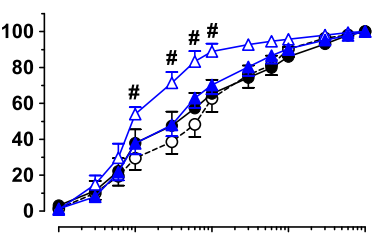

\section{K}

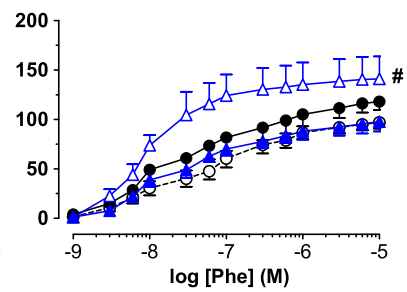

D Sugen+Hypoxia

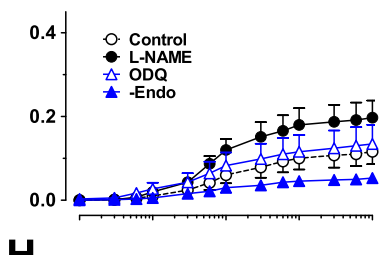

$\mathbf{H}$

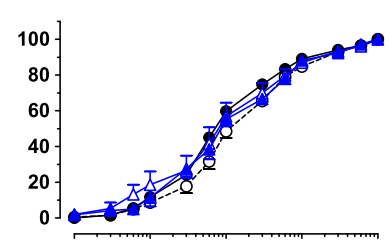

$\mathbf{L}$

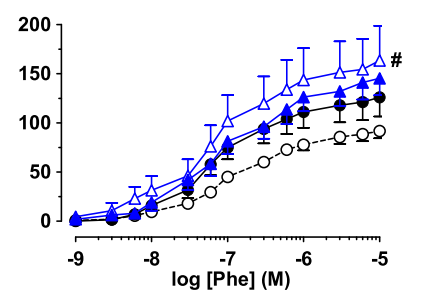

Fig. 4. Effect of endothelium removal or blockade of NO-cGMP pathway on Phe-induced contraction of pulmonary artery. Isolated pulmonary artery rings from $\mathrm{Nx}, \mathrm{Hx}, \mathrm{Su}$, and $\mathrm{Su} / \mathrm{Hx}$ rats were kept endothelium-intact (open circles), pretreated with the NOS inhibitor L-NAME (3 $\left.\times 10^{-4} \mathrm{M}\right)($ closed circles) or the guanylate cyclase inhibitor ODQ $\left(10^{-5} \mathrm{M}\right)$ (open triangles) for 15 minute, or endothelium-denuded (closed triangles). The vessels were stimulated with increasing concentrations of Phe, and the contractile response was presented in grams per milligram of tissue (A-D), as the percentage of maximum Phe contraction (E-H), or as the percentage of control $96 \mathrm{mM} \mathrm{KCl}$ contraction (I-L). Data represent means \pm S.E.M., $n=7-11$. * $P<0.05$, L-NAME-treated versus control nontreated vessels. ${ }^{\#} P<0.05$, ODQ-treated versus control nontreated vessels.

compared with $\mathrm{Nx}$ rats (Fig. 7A). In contrast, nitrate/nitrite production in response to ACh was not significantly altered in the aorta and mesenteric artery of the different groups (Fig. 7, $\mathrm{B}$ and $\mathrm{C})$.

In pulmonary artery segments precontracted with submaximal Phe concentration, the exogenous NO donor sodium nitroprusside (SNP) caused concentration-dependent relaxation that was not different in $\mathrm{Hx}$ or Su rats compared with $\mathrm{Nx}$ arts but was significantly reduced in $\mathrm{Su} / \mathrm{Hx}$ rats compared with $\mathrm{Nx}, \mathrm{Hx}$, and Su rats, particularly at lower SNP concentrations (Fig. 8A), suggesting decreased responsiveness of VSMCs to vasodilators. In comparison, SNP-induced relaxation was not significantly different in the aorta or mesenteric artery of the different groups (Fig. 8, B and C).

Lung Histology, Morphometric Analysis, and Pulmonary Artery Gene Expression Analysis. In lung tissue sections stained with $\mathrm{H} \& \mathrm{E}$, the percentage of the wall thickness of the pulmonary arterioles was significantly greater in the $\mathrm{Su} / \mathrm{Hx}$ group compared with the $\mathrm{Nx}$ group (Fig. 9). Real-time PCR analysis of pulmonary arteries harvested from our experimental animals demonstrated significantly lower levels of a panel of contractile markers in the $\mathrm{Su} / \mathrm{Hx}$ group compared with the $\mathrm{Nx}$ group (Fig. 10). These markers are components of the VSMC contractile apparatus and include $\alpha$ smooth muscle actin, calponin, myosin heavy chain, smoothelin, and transgelin (also known as SM22a). In contrast, there was a trend for increased mRNA of the synthetic or dedifferentiation marker for VSMCs retinolbinding protein-1 in the $\mathrm{Su} / \mathrm{Hx}$ compared with the $\mathrm{Nx}$ group.

\section{Discussion}

The major novel findings of our study in the Su/Hx rat model of severe $\mathrm{PH}$ are: 1) decreased pulmonary artery contraction in response to Phe and $\mathrm{KCl}, 2$ ) decreased relaxation of pulmonary artery to ACh and SNP, 3) decreased pulmonary vascular production and responsiveness to the NO-cGMP relaxation pathway, and 4) downregulation of contractile markers in pulmonary arteries. These findings are specific to the pulmonary circulation and are in the context of elevated RVSP, right ventricular hypertrophy (RVH), and pulmonary vascular remodeling in this model.

Regulation of pulmonary vascular tone is achieved by the balance between vasoconstrictor and vasodilator stimuli that are responsive to changing physiologic needs. A pathologic shift in this balance is known to contribute to the development of $\mathrm{PH}$ in human patients and in preclinical models of the disease (Gillespie et al., 1986; Adnot et al., 1991; Fullerton et al., 1996; Geraci et al., 1999; Shimoda et al., 2000b; Hoshikawa et al., 2001; Ivy et al., 2002; Fagan et al., 2004; Ambalavanan et al., 2005; Schermuly et al., 2005; Homma et al., 2007). This knowledge has formed the basis of all current therapies that either enhance vasodilator mechanisms, such as the prostacyclin-cAMP pathway and the 


\section{Endothelium-Dependent ACh-Induced Relaxation}
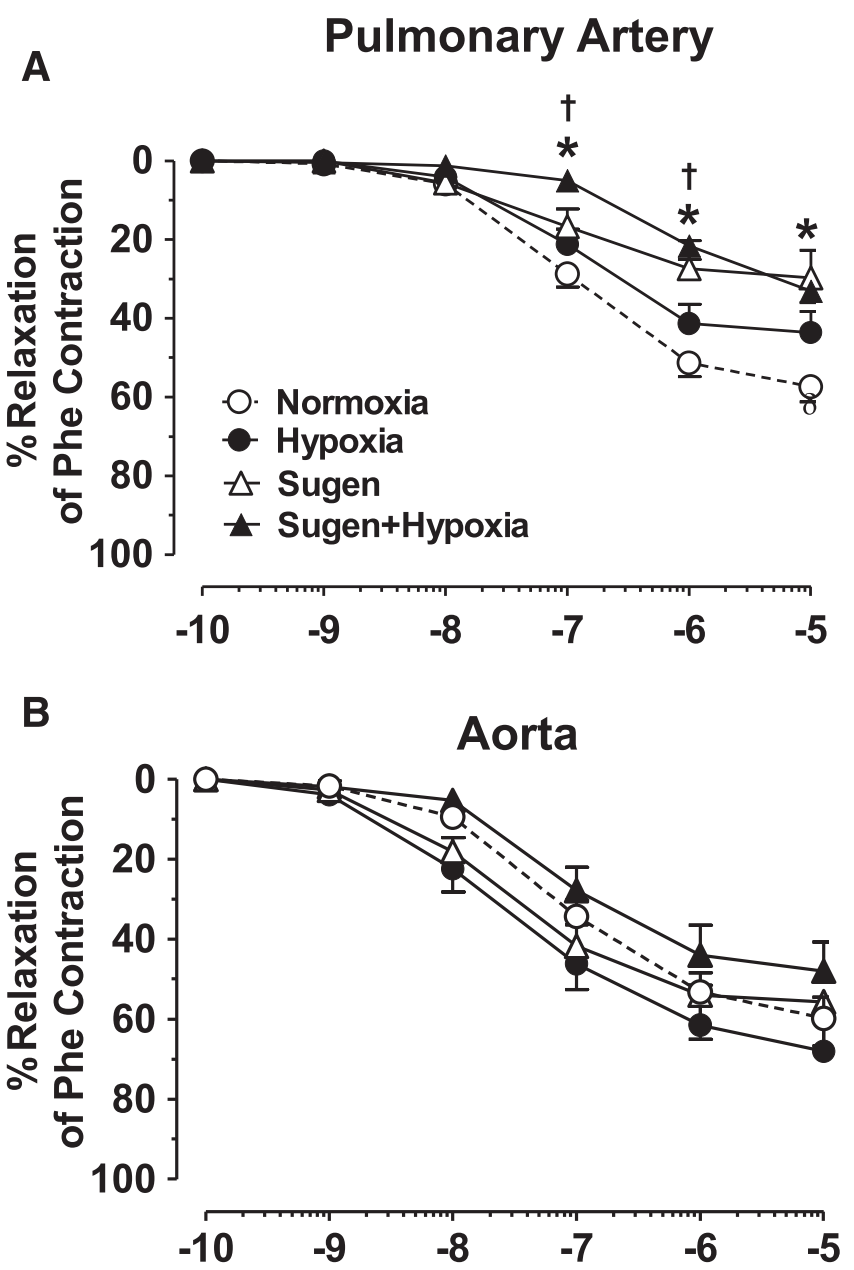

Fig. 5. ACh-induced relaxation in blood vessels of $\mathrm{Nx}$, $\mathrm{Hx}, \mathrm{Su}$, and $\mathrm{Su} / \mathrm{Hx}$ rats. Pulmonary artery (A), aortic (B), and mesenteric artery rings (C) from $\mathrm{Nx}, \mathrm{Hx}, \mathrm{Su}$, and $\mathrm{Su} / \mathrm{Hx}$ rats were stimulated with submaximal concentration of Phe, then stimulated with ACh $\left(10^{-9}-10^{-5} \mathrm{M}\right)$, and the percentage of relaxation of Phe contraction was measured. Data represent means \pm S.E.M., $n=7-11 .{ }^{*} P<0.05$ versus $\mathrm{Nx} .{ }^{\dagger} P<0.05$ versus $\mathrm{Hx}$.

C

Mesenteric Artery

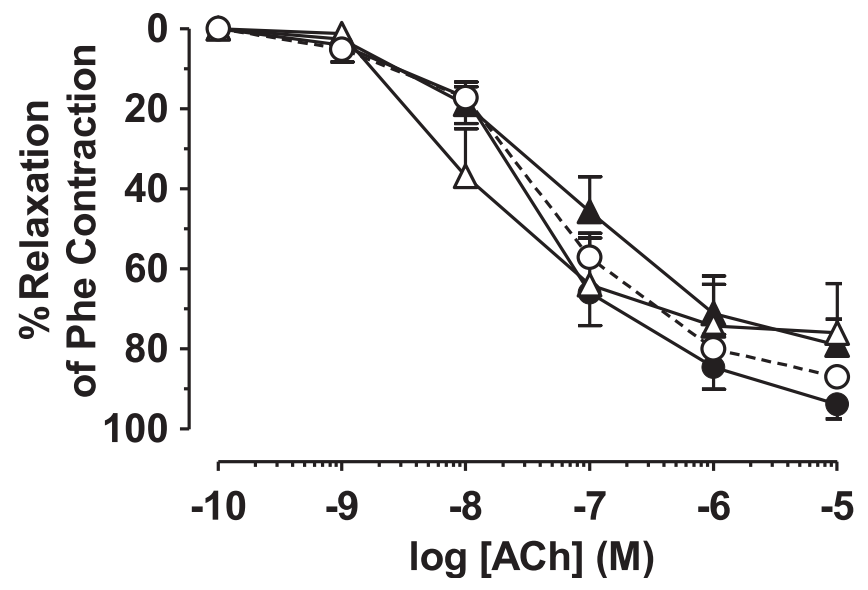

NO-cGMP pathway, or inhibit vasoconstrictor mechanisms, such as the endothelin and intracellular $\mathrm{Ca}^{2+}$ pathways (Lee et al., 2008; Burger, 2009; Stehlik and Movsesian, 2009; Yin et al., 2009); however, altered vascular tone is not always the predominant pathogenetic mechanism since many patients have a "fixed" component in their disease, and this, unfortunately, is not optimally responsive to current vasodilator therapies. This "fixed" component is largely due to excessive pulmonary vascular remodeling owing to the altered biology of various cell types at the pulmonary vascular wall. 
Effect of Endothelium Blockade or Removal on ACh Relaxation of Pulmonary Artery

A

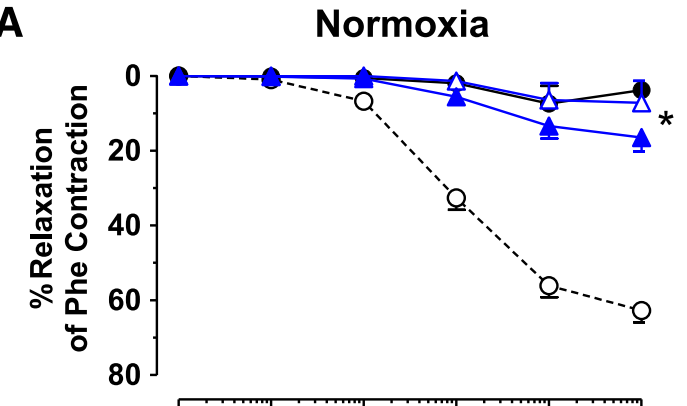

C

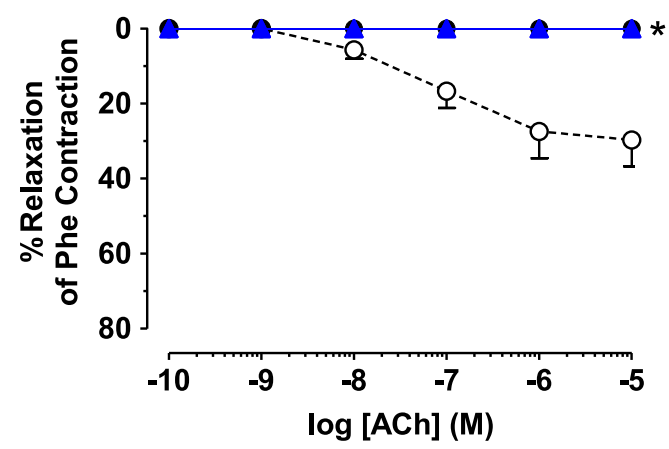

B

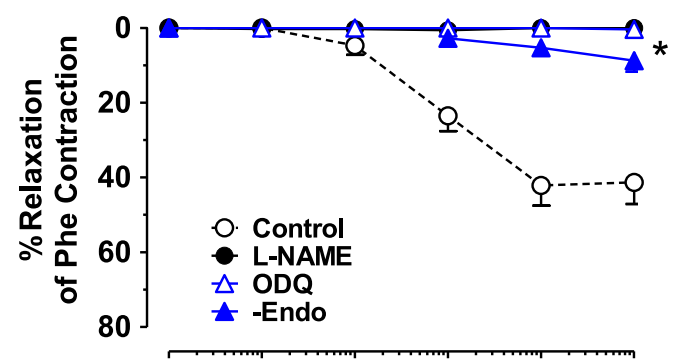

D

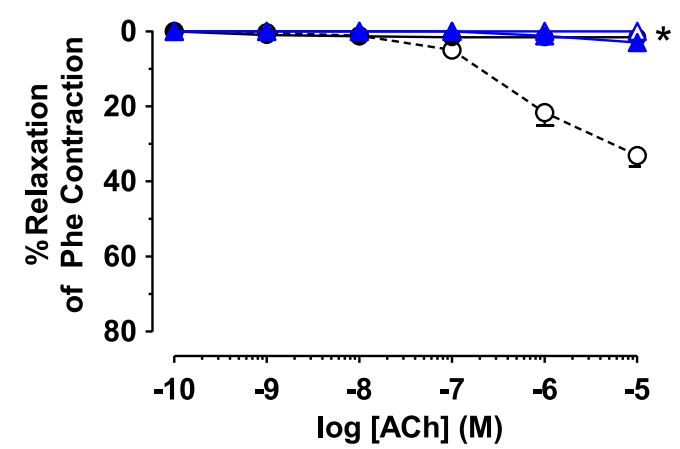

Fig. 6. Effect of endothelium removal or blockade of NO-cGMP pathway on ACh-induced relaxation of pulmonary artery. Isolated pulmonary artery rings from $\mathrm{Nx}, \mathrm{Hx}, \mathrm{Su}$, and $\mathrm{Su} / \mathrm{Hx}$ rats were either kept endothelium-intact (open circles), pretreated with the NOS inhibitor L-NAME $\left(3 \times 10^{-4} \mathrm{M}\right.$ ) (closed circles) or the guanylate cyclase inhibitor ODQ $\left(10^{-5} \mathrm{M}\right)$ (open triangles) for 15 minutes, or endothelium-denuded (closed triangles). The vessels were stimulated with submaximal concentration of Phe, then stimulated with ACh $\left(10^{-9}-10^{-5} \mathrm{M}\right)$, and the percentage of relaxation of Phe contraction was measured. Data represent means \pm S.E.M., $n=7-11$. ${ }^{*} P<0.05$, vessels treated with L-NAME or ODQ or endothelium denuded vs. control nontreated endothelium-intact vessels.

Accumulating evidence in both human and animal studies supports that pulmonary vascular smooth muscle cell phenotypic switch from a contractile to a synthetic and proliferative phenotype is one of the underlying pathogenetic mechanisms in PH (Michelakis et al., 2002; McMurtry et al., 2004, 2005; Bonnet et al., 2007; Li et al., 2009), raising the exciting possibility for a novel therapeutic strategy aiming to restore a contractile pulmonary VSMC phenotype and reverse structural remodeling, which is likely to ameliorate vascular dysfunction and enhance responsiveness to vasodilator therapies.

Since PH is a rare and heterogeneous disease, several animal models have been developed that share many features of the human disease and have provided insights into pathogenetic mechanisms. We and others previously studied pulmonary vascular function in the $\mathrm{Hx}$ and monocrotaline models of $\mathrm{PH}$ and found significant impairments in pulmonary vascular responsiveness, along with significant hemodynamic and structural changes in the pulmonary circulation (Christou et al., 2000; Hoshikawa et al., 2003; Schermuly et al., 2004; Arciniegas et al., 2007; Nozik-Grayck and Stenmark, 2007; Majka et al., 2008). These changes were pulmonary vascular bed-specific since we did not find major effects in the systemic circulation. The mechanisms for pulmonary vascular bed specificity in these animal models may relate to differential sensitivity of pulmonary vascular cells owing to their baseline physiologic exposure to hypoxia or to differences in the way vascular cells from different beds sense, signal, and respond to adverse stimuli. In our prior studies, we found that these changes can be targeted by therapeutic interventions that seem to restore a contractile pulmonary vascular smooth muscle cell phenotype (Christou et al., 2012). The adult rat $\mathrm{Su} / \mathrm{Hx}$ model of severe PH was described by TarasevicieneStewart and coworkers (Taraseviciene-Stewart et al., 2001) and is thought to more closely recapitulate the human condition because of the similarities in pulmonary vascular pathology, its progressive nature, and its ultimate lethality. In this model, despite the systemic administration of Su and the global effects of exposure to hypoxia, the vascular pathology seems to be pulmonary vascular bed-specific. The underlying changes in pulmonary vascular function in this model have not been previously studied. Also, the effects on systemic vascular function in the $\mathrm{Su} / \mathrm{Hx}$ model were not previously described. We thus examined vascular reactivity in pulmonary and systemic vessels to better understand the vascular mechanisms underlying $\mathrm{PH}$ in the $\mathrm{Su} / \mathrm{Hx}$ model.

Our hemodynamic measurements confirm that the $\mathrm{Su} / \mathrm{Hx}$ rat model of $\mathrm{PH}$ is characterized by more severe $\mathrm{PH}$ than that induced by hypoxia or sugen alone. Consistent with previous reports (de Raaf et al., 2014), the RVSP was greater in $\mathrm{Su} / \mathrm{Hx}$ compared with $\mathrm{Nx}, \mathrm{Hx}$, or Su rats. Also, the Fulton's index and the RV/Body weight ratio, as measures of right ventricular hypertrophy, were greater in $\mathrm{Su} / \mathrm{Hx}$ compared with $\mathrm{Nx}, \mathrm{Hx}$, and $\mathrm{Su}$ rats. These findings are consistent with previous reports that demonstrate that hypoxia-induced $\mathrm{PH}$ is spontaneously reversible upon return to normoxia (de Raaf et al., 
Nitric Oxide Production

A Pulmonary Artery
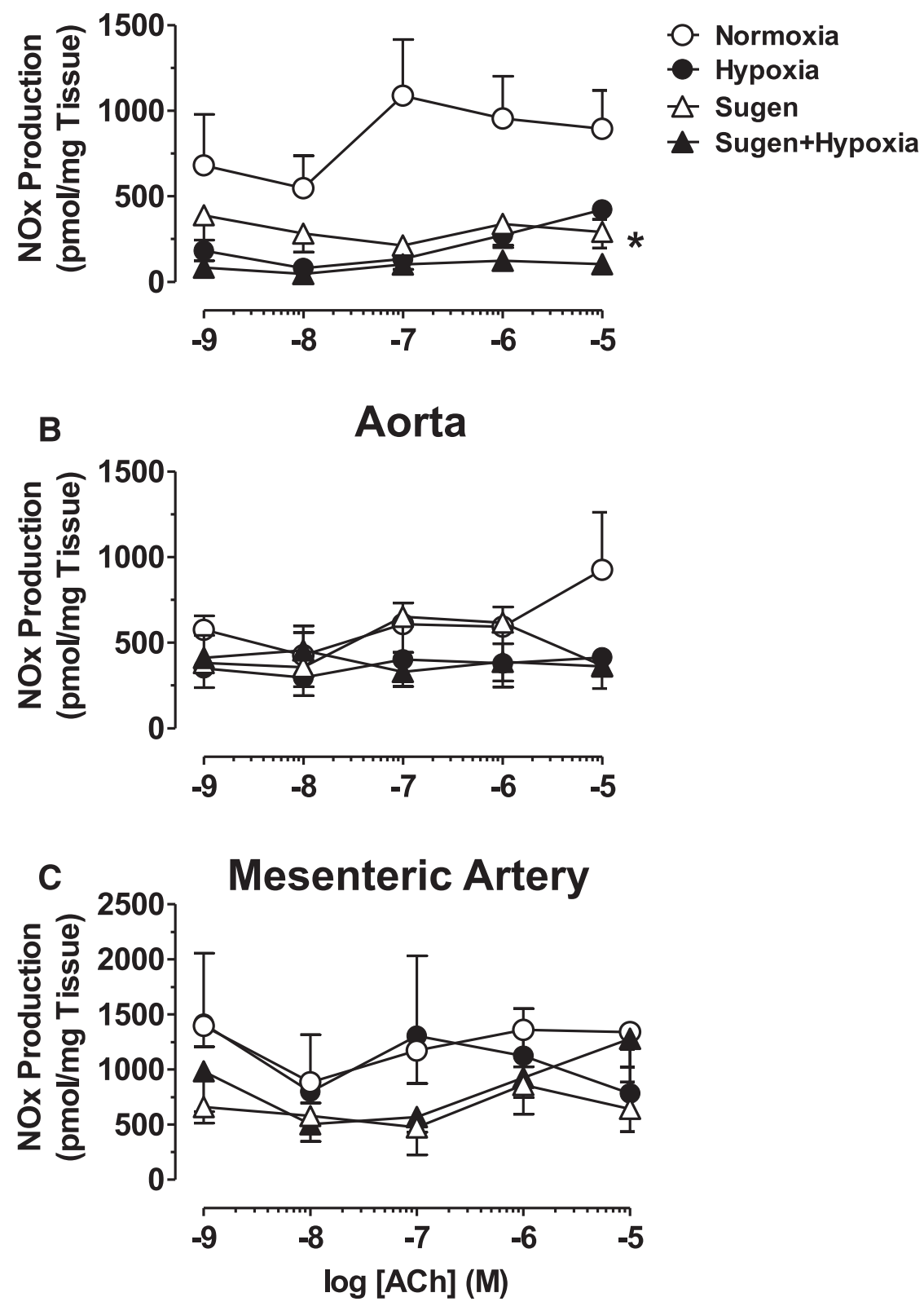

2014) and that treatment with sugen alone is inconsistent in producing sustained $\mathrm{PH}$ likely because of individual animal variability in susceptibility (Jiang et al., 2015). The combination of $\mathrm{Su} / \mathrm{Hx}$ produced a robust increase in all components of $\mathrm{PH}$ (RVSP, RVH, and structural remodeling) and thus support that this is a suitable model to examine the vascular mechanisms underlying severe $\mathrm{PH}$.

We measured the responses to the $\alpha$-adrenergic receptor agonist Phe, a potent vasoconstrictor (Leblais et al., 2004), and found that pulmonary artery contraction to Phe was markedly reduced in $\mathrm{Su} / \mathrm{Hx}$ rats compared with $\mathrm{Nx}$ rats. The reduction in Phe contraction of pulmonary artery cannot be attributed to $\mathrm{Hx}$ alone or $\mathrm{Su}$ alone because of the following:
Fig. 7. NO production in the blood vessels of $\mathrm{Nx}, \mathrm{Hx}$, $\mathrm{Su}$, and $\mathrm{Su} / \mathrm{Hx}$ rats. Pulmonary artery (A), aortic (B), and mesenteric artery rings $(\mathrm{C})$ from $\mathrm{Nx}, \mathrm{Hx}, \mathrm{Su}$, and $\mathrm{Su} / \mathrm{Hx}$ rats were stimulated with increasing concentrations of $\mathrm{ACh}$, and $\mathrm{NOx}$ ) production was measured. Data represent means \pm S.E.M., $n=7-11$. ${ }^{*} P<0.05$ versus Nx.
1) the pulmonary artery contraction to Phe was not different in Hx compared with Nx rats; previous studies have suggested that a hallmark of hypoxic $\mathrm{PH}$ is an increase in vasomotor tone (Shimoda et al., 2000a; Oka et al., 2007). For instance, chronic $\mathrm{Hx}$ may increase the production/activity of vasoconstrictors, such as endothelin-1 (ET-1) and angiotensin II in the lung (Shimoda et al., 2000b) or induce direct effects on pulmonary VSMCs, modulating receptor population, ion channel activity, $\mathrm{K}^{+}$current, membrane depolarization, elevation in cytosolic $\mathrm{Ca}^{2+}$ (Shimoda et al., 2000b), or signal transduction pathways, such as Rho kinase (Oka et al., 2007). We have previously shown that $\mathrm{Hx}$ treatment of 2 weeks was sufficient to cause decreases in pulmonary artery contraction to Phe 


\section{Endothelium-Independent Relaxation}

A Pulmonary Artery

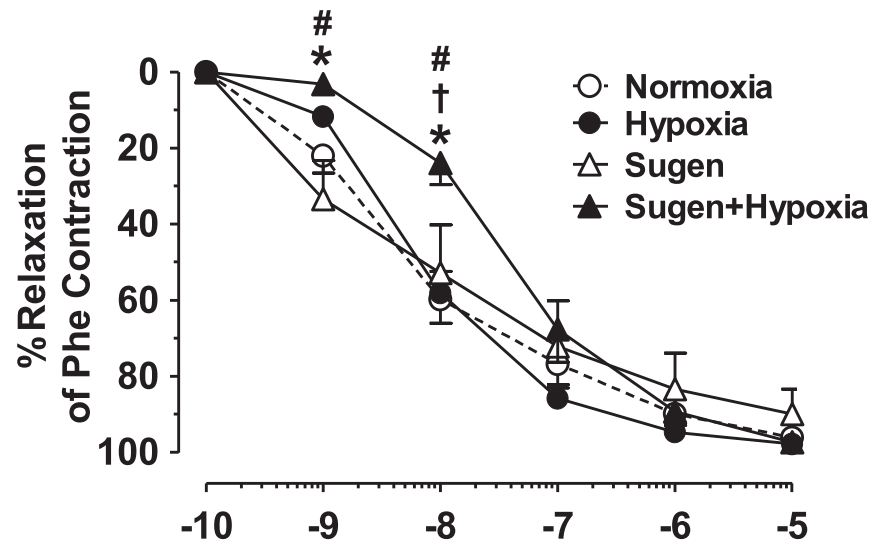

B
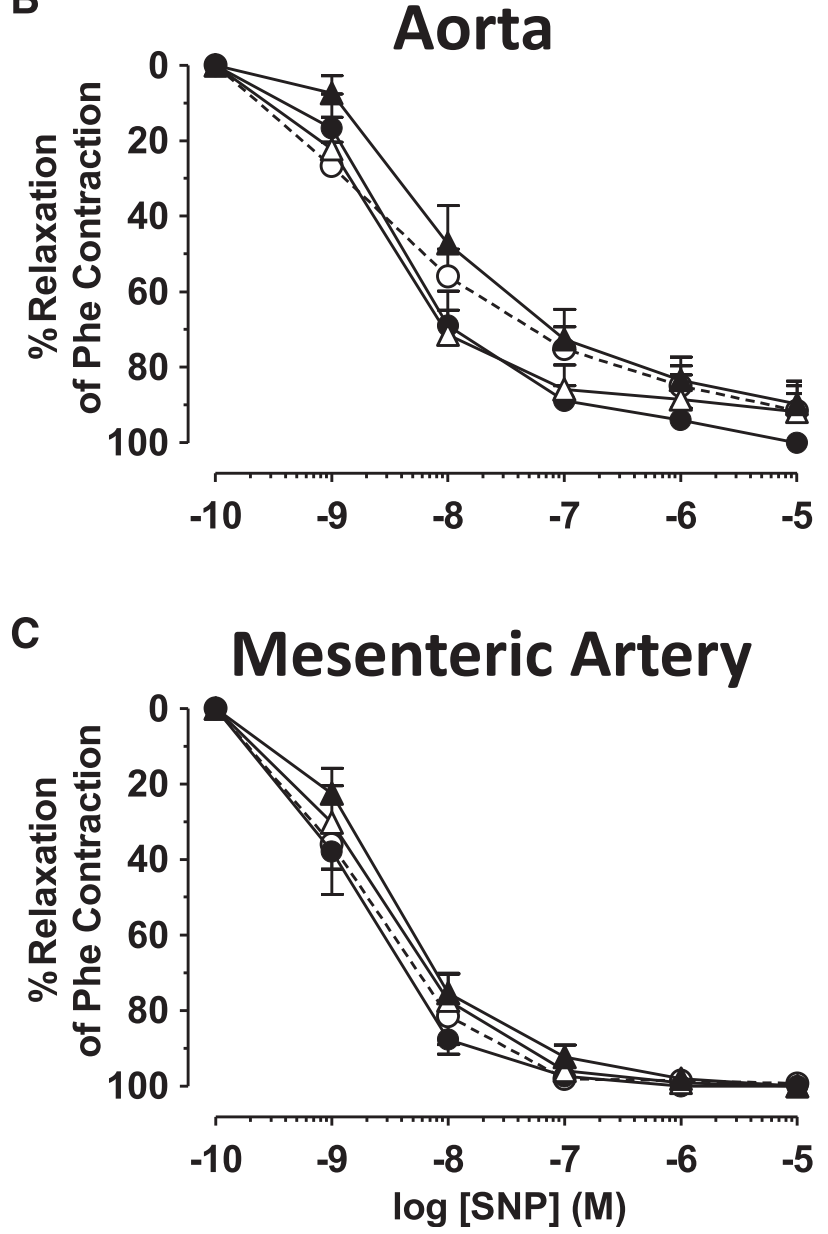

Fig. 8. SNP-induced relaxation in blood vessels of $\mathrm{Nx}, \mathrm{Hx}, \mathrm{Su}$, and $\mathrm{Su} / \mathrm{Hx}$ rats. Endothelium-denuded pulmonary artery (A), aortic (B), and mesenteric artery rings (C) from $\mathrm{Nx}, \mathrm{Hx}, \mathrm{Su}$, and $\mathrm{Su} / \mathrm{Hx}$ rats were precontracted with submaximal concentration of Phe, then stimulated with SNP $\left(10^{-9}-10^{-5} \mathrm{M}\right)$, and the percentage of relaxation of Phe contraction was measured. Data represent means \pm S.E.M., $n=7-11$. $* P<0.05$ versus Nx. ${ }^{\dagger} P<0.05$ versus $\mathrm{Hx}$. ${ }^{\#} P<0.05$ versus $\mathrm{Su}$.
(Christou et al., 2012); this was consistent with another report by Itoh et al. (1999), in which endothelin-1 (ET-1)-induced vasoconstriction of pulmonary artery strips was reduced in the $\mathrm{Hx}$ rat model of $\mathrm{PH}$ (Itoh et al., 1999). The difference in the results of the various studies could be due to differences in the vasoconstrictive agonists used (Phe vs. ET-1 or angiotensin II) or the vascular preparation used (pulmonary artery vs. isolated perfused lungs). Also, our previous study was done immediately after 2 weeks of hypoxic exposure, whereas in the current study, we exposed animals to hypoxia for 3 weeks and 
A

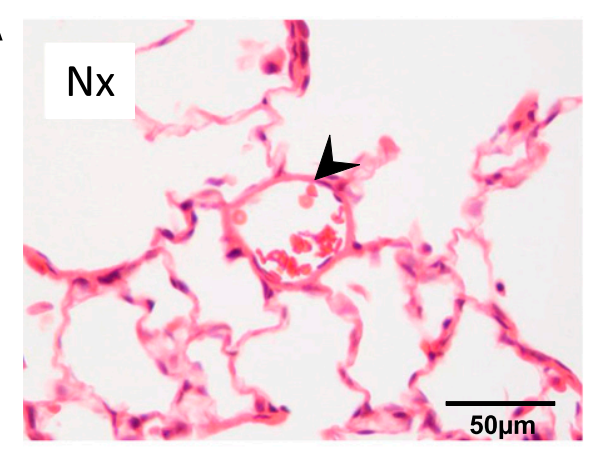

C

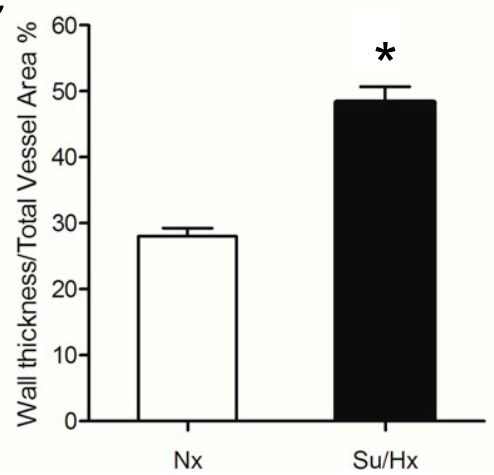

B

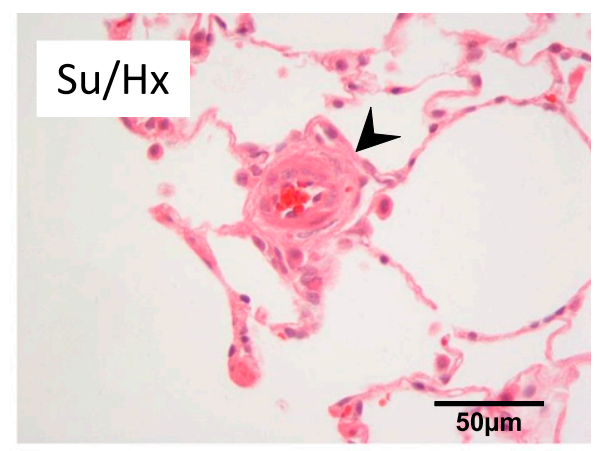

Fig. 9. Pulmonary vascular remodeling in the $\mathrm{Su} / \mathrm{Hx}$-model of pulmonary hypertension. Representative H\&E-stained peripheral lung sections from each experimental group (Nx, A; Su/Hx, B). Pulmonary arterioles are indicated with arrowheads. Scale bar, $50 \mu \mathrm{m}$. Quantitative morphometric analysis of the percentage of the wall thickness of pulmonary arterioles defined as the area occupied by the vessel wall divided by the total cross sectional area of the arteriole (C). Graph bars represent means \pm S.E.M. of 30-52 vessels from five rats per group. $* P<0.05$. allowed them to recover for 4 weeks in normoxia. Our results are in accordance with previous studies in which hemodynamic changes improve in the hypoxic model after the animals return to normoxia (de Raaf et al., 2014). 2) The pulmonary artery contraction to Phe was slightly increased in $\mathrm{Su}$ compared with $\mathrm{Nx}$ rats, consistent with reports that $\mathrm{Su}$ is a potent VEGF receptor antagonist (O'Farrell et al., 2004), and is therefore expected to decrease vascular relaxation and in turn enhance vascular contraction. 3) The pulmonary artery contraction to Phe was significantly reduced in $\mathrm{Su} / \mathrm{Hx}$ compared with $\mathrm{Su}$ alone rats, suggesting that combined $\mathrm{Su} / \mathrm{Hx}$ was necessary for the induction of the significant pulmonary pathology. 4) The changes in Phe contraction appear to be specific to the pulmonary artery, as the Phe contraction in other systemic arteries such as the aorta and mesenteric artery did not differ among the different groups of rats.

The interaction of Phe with $\alpha$-adrenergic receptors is coupled to activation of GTP-binding protein and various $\mathrm{Ca}^{2+}$-dependent and $\mathrm{Ca}^{2+}$-independent mechanisms of VSM contraction (Dallas and Khalil, 2003). The observed decrease in Phe contraction of pulmonary artery may be due in part to changes in the sensitivity of $\alpha$-adrenergic receptors or affinity to Phe because the Phe $\mathrm{ED}_{50}$ was reduced in $\mathrm{Su} / \mathrm{Hx}$ compared with $\mathrm{Nx}, \mathrm{Hx}$, and $\mathrm{Su}$ rats. Also, the contraction of pulmonary artery to membrane depolarization by high $\mathrm{KCl}$, a receptorindependent response that involves stimulation of $\mathrm{Ca}^{2+}$ entry through voltage gated channels (Murphy et al., 2001; Mazzuca et al., 2015), was reduced in $\mathrm{Su} / \mathrm{Hx}$ compared with $\mathrm{Nx}$ rats, suggesting that the reduced pulmonary vascular response could be due partly to decreased $\mathrm{Ca}^{2+}$ entry mechanisms into VSMCs or other postreceptor mechanisms of VSMC contraction, and these possibilities should be verified by measuring cytosolic $\mathrm{Ca}^{2+}$ concentration and other contraction mechanisms in pulmonary arterial smooth muscle cells in future experiments. Interestingly, when the Phe response was measured as the percentage of control $\mathrm{KCl}$ contraction, the Phe response was still reduced in $\mathrm{Su} / \mathrm{Hx}$ compared with $\mathrm{Nx}$, $\mathrm{Hx}$, and $\mathrm{Su}$ rats. These observations suggest other mechanisms that could reduce contraction in pulmonary VSMCs of the $\mathrm{Su} / \mathrm{Hx}$ model of $\mathrm{PH}$. High $\mathrm{KCl}$-depolarizing solution affects the $\mathrm{K}^{+}$gradient across the plasma membrane and is therefore expected to affect the outward movement of $\mathrm{K}^{+}$ion and the activity of $\mathrm{K}$ channels. Different types of $\mathrm{K}^{+}$channels have been described in VSMCs, and whether the activity of $\mathrm{K}^{+}$ channels is altered in $\mathrm{Su} / \mathrm{Hx}$ model remains to be examined. Our gene expression analysis in isolated pulmonary arteries from $\mathrm{Su} / \mathrm{Hx}$ animals supports that there is a pattern of dedifferentiation as assessed by decreased abundance of five contractile markers. This finding is in accord with prior studies that reported evidence of VSMC dedifferentiation in other models of PH, as well as human PAH (Li et al., 2009; Xiao et al., 2013). Future studies should examine whether the changes in mRNA expression of contractile markers translate into changes in protein levels using Western blot analysis.

We examined whether the impaired pulmonary vasoconstriction in $\mathrm{Su} / \mathrm{Hx}$ rats could be attributed to enhanced release of endothelium-derived relaxing factor (EDRF). The endothelium is known to release nitric oxide (NO) (Busse and Fleming, 1999) prostacyclin (Parkington et al., 2004), and EDHF (Félétou and Vanhoutte, 2006). NO is known to diffuse into VSMCs, where it activates guanylate cyclase and increase cGMP. cGMP in turn would promote relaxation by decreasing intracellular $\mathrm{Ca}^{2+}$ or reducing the $\mathrm{Ca}^{2+}$ sensitivity of the contractile proteins. Our ACh experiments in Nx rats demonstrate an intact endothelium-dependent relaxation of pulmonary artery that is abolished by endothelium removal. Also, the observations that the NOS inhibitor L-NAME and guanylate cyclase inhibitor ODQ blocked ACh relaxation in the pulmonary artery suggest a role of the NO-cGMP relaxation pathway. The NO-cGMP pathway appears to be impaired in 
A

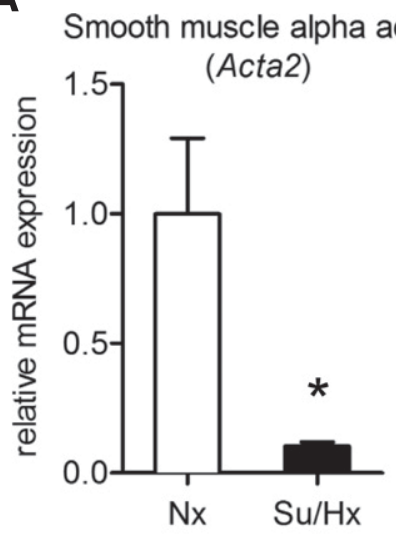

D

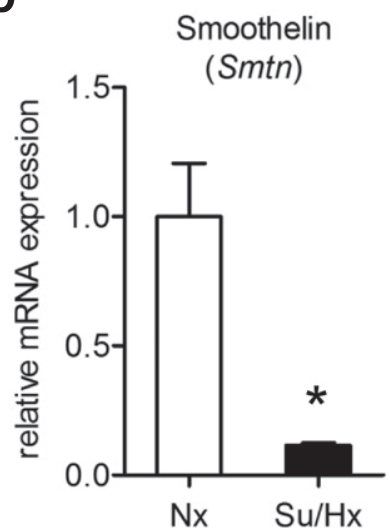

B

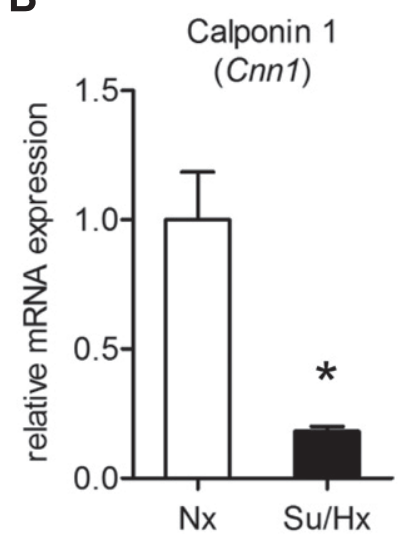

E

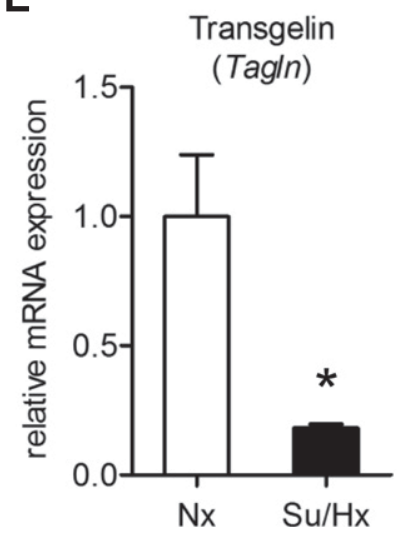

C

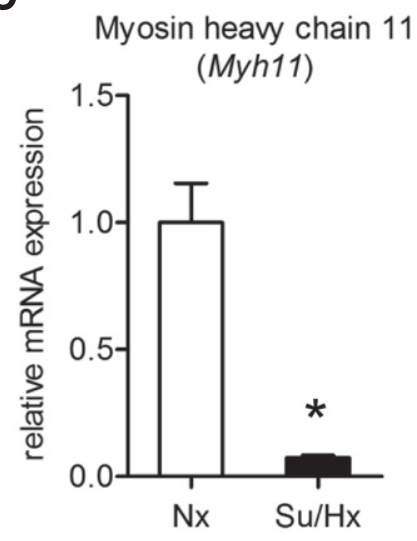

$\mathbf{F}$

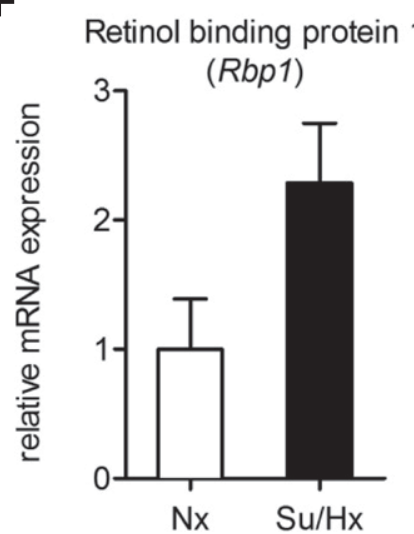

Fig. 10. Pulmonary artery smooth muscle cell de-differentiation in the Su/Hx-induced model of PH. Expression of contractile (A-E) and synthetic (F) markers were analyzed in pulmonary arteries of $\mathrm{Nx}$ and $\mathrm{Su} / \mathrm{Hx}$ animals by RT-qPCR. All contractile markers are significantly downregulated in Su/Hx animals. Definition of genes: smooth muscle $\alpha$-actin (Acta2, A), calponin1 (Cnn1, B), myosin heavy chain 11 (Myh11, C), smoothelin (Smtn, D), transgelin $(T a g l n, \mathrm{E})$, and retinol-binding protein $(R b p 1, \mathrm{~F})$. Graph bars represent means \pm S.E.M. $N=5-7$ rats per experimental group. ${ }^{*} P<0.05$.

the pulmonary artery of $\mathrm{Su} / \mathrm{Hx}$ rats. This result is supported by the following findings: 1) ACh-induced relaxation was not different from $\mathrm{Nx}$ rats in the pulmonary artery of $\mathrm{Hx}$ rats, partially reduced in $\mathrm{Su}$ rats, and significantly reduced in $\mathrm{Su} / \mathrm{Hx}$ rats compared with $\mathrm{Nx}$ and $\mathrm{Hx}$ rats; 2) the reduction in $\mathrm{ACh}$ relaxation in $\mathrm{Su} / \mathrm{Hx}$ rats compared with other groups was specific to the pulmonary artery and was not observed in the aorta or mesenteric artery; 3) blockade of NO production by L-NAME enhanced Phe contraction as the percentage of $\mathrm{KCl}$ in $\mathrm{Nx}$ rats but not in $\mathrm{Hx}, \mathrm{Su}$, and $\mathrm{Su} / \mathrm{Hx}$ rats, suggesting that the $\mathrm{NO}$ pathway is intact in $\mathrm{Nx}$ rats but impaired in $\mathrm{Hx}, \mathrm{Su}$, and $\mathrm{Su} / \mathrm{Hx}$ rats; and 4) NO production was reduced in the pulmonary artery of $\mathrm{Su} / \mathrm{Hx}$ rats compared with $\mathrm{Nx}$ rats, and the reduction was not observed in the aorta or mesenteric artery.

Other alterations in the NO-cGMP pathway were also observed among the different groups of rats. NO production was significantly reduced in the pulmonary artery of Su-alone rats. This observation is consistent with the observed decrease in $\mathrm{ACh}$ relaxation in $\mathrm{Su}$ alone rats and could be related to Su-induced blockade of the effects of VEGF and resulting endothelial cell dysfunction. Also, NO production was reduced in pulmonary artery of $\mathrm{Hx}$ rats compared with $\mathrm{Nx}$ rats, although ACh relaxation did not differ between the two groups, likely because ACh relaxation may also involve other pathways such as prostacyclin $\left(\mathrm{PGI}_{2}\right)$ and EDHF (Majed and Khalil, 2012; Mazzuca et al., 2015); these pathways may still be functional in the Hx rats and should be examined in future studies. Also, despite the marked decrease in NO production that is expected to cause a decrease in guanylate cyclase activity, ODQ caused significant enhancement of Phe contraction as a percentage of $\mathrm{KCl}$ in $\mathrm{Su}$-alone and in $\mathrm{Su} / \mathrm{Hx}$ rats. This finding could be partly explained by possible compensatory increase in guanylate cyclase activity to rescue against the marked decrease in $\mathrm{NO}$ in the $\mathrm{Su}$ rats and $\mathrm{Su} / \mathrm{Hx}$ rats. Although we did not directly measure $\mathrm{Ca}^{2+}$ sensitivity, assuming that $\mathrm{KCl}$ contraction is mainly due to $\mathrm{Ca}^{2+}$ influx (Murphy and Khalil, 2000), then the enhanced Phe contraction as a percentage of $\mathrm{KCl}$ contraction in ODQ-treated guanylate cyclase-blocked pulmonary artery of $\mathrm{Su}$ and $\mathrm{Su} / \mathrm{Hx}$ rats is likely due to activation of $\mathrm{Ca}^{2+}$-sensitization pathways, such as protein kinase C or Rho-kinase (Weigand et al., 2011), and the contribution of these pathways to pulmonary artery contraction in the $\mathrm{Su} / \mathrm{Hx}$ animal models of $\mathrm{PH}$ should be further examined. The changes in $\mathrm{Ca}^{2+}$ sensitization pathways were not observed in control nontreated vessels because they were likely obscured by compensatory increased guanylate cyclase activity, and only with blockade of guanylate cyclase could the enhanced contraction mechanisms be manifested. This result is supported by reports that cGMP reduces 
$\left[\mathrm{Ca}^{2+}\right]_{\mathrm{i}}$ (Lincoln et al., 1990), and cGMP-dependent protein kinase causes phosphorylation and inhibition of myosin light chain kinase and $\mathrm{Ca}^{2+}$ sensitization pathways (Salamanca and Khalil, 2005). Interestingly, Rho kinase has been suggested to play a role in $\mathrm{PH}$, and Rho kinase inhibitors have been effective as potential therapies in experimental $\mathrm{PH}$ (Oka et al., 2008) Whether the changes in the $\mathrm{Ca}^{2+}$ sensitization mechanisms of VSM contraction are directly caused by $\mathrm{Hx}, \mathrm{Su}$, or both is unclear and needs to be further examined.

SNP is an exogenous NO donor that causes direct stimulation of guanylate cyclase and increase in cGMP levels. In the present study, SNP-induced pulmonary artery relaxation was not different in the pulmonary artery of $\mathrm{Hx}$ or Su-alone rats, but it was significantly reduced in $\mathrm{Su} / \mathrm{Hx}$ rats. Also, the reduction in SNP relaxation in $\mathrm{Su} / \mathrm{Hx}$ rats was specific to the pulmonary artery and was not observed in the aorta and mesenteric artery. These observations suggest that in addition to the reduced NO production, the reduced pulmonary artery relaxation to $\mathrm{SNP}$ in $\mathrm{Su} / \mathrm{Hx}$ rats may be related to structural changes in the pulmonary vascular wall that lead to decreased responsiveness of pulmonary VSMCs to vasodilators. Previous studies have shown that ACh-induced relaxation in isolated perfused lung preparations is reduced in rats exposed to $\mathrm{Hx}$ for 1 week and abolished after 3 weeks of $\mathrm{Hx}$ exposure (Adnot et al., 1991). Other studies have shown enhanced pressor response to ET-1 in Hx rats compared with controls with no potentiation of the pressor response by EDRF antagonists (hydroquinone, methylene blue, and pyrogallol); however, the endothelium-independent vasodilation by SNP was fully active in $\mathrm{Hx}$ rats, and we concluded that $\mathrm{Hx}$-induced $\mathrm{PH}$ is associated with a loss of EDRF activity in pulmonary vessels (Adnot et al., 1991). On the other hand, our observation that both ACh- and SNP-induced relaxation is reduced in pulmonary arteries of $\mathrm{Su} / \mathrm{Hx}$ rats is similar to the results in the monocrotaline model of progressive lung injury and $\mathrm{PH}$, where both endothelial-dependent and endothelialindependent relaxation were reduced (Fullerton et al., 1996). Taken together, these observations suggest that the decreased ACh- and SNP-induced relaxation in pulmonary artery of $\mathrm{Su} / \mathrm{Hx}$ rats is due to a reduction in NO production, as well as structural changes in the pulmonary vascular wall that lead to a decreased responsiveness of pulmonary VSMCs to vasodilators. Other potential factors that could contribute to the observed decreased responsiveness to SNP in the $\mathrm{Su} / \mathrm{Hx}$ model may include increased phosphodiesterase-5 activity or decreased protein kinase $\mathrm{G}$ activity, and this possibility should be examined in future studies. A prior report showed that maximal ACh-induced relaxation was reduced in extralobar first-branch pulmonary artery rings of $\mathrm{Su} / \mathrm{Hx}$ model in Fischer 344 rats (Alzoubi et al., 2013). Whereas the present study also showed impaired ACh relaxation in extralobar pulmonary artery rings, it was conducted in a $\mathrm{Su} / \mathrm{Hx}$ model in a different strain of rats (Sprague-Dawley). Also, our study provided more in-depth analysis of the ACh concentration-response curve, the endothelium-dependent $\mathrm{ACh}$ response versus endothelium-independent SNP response, and more mechanistic information regarding the role of NO-cGMP pathway and the sensitivity of this pathway to inhibitors of NOS and guanylate cyclase (L-NAME and ODQ) and endothelium removal, as well as direct measurements of NO metabolites. Furthermore, the present study showed that the reduced endothelium-dependent and endothelium-independent relaxation pathways were specific to the pulmonary artery of $\mathrm{Su} / \mathrm{Hx}$ rats and were not observed in the aorta or mesenteric artery. Thus, the present study demonstrates impaired endothelium-dependent as well as endothelium-independent pulmonary artery relaxation. It would be important to test whether infusion of vasodilators in the $\mathrm{Su} / \mathrm{Hx}$ model in vivo affects pulmonary arterial pressure. Interestingly, a recent study demonstrated that acute intravenous infusion of the vasodilator agent adenosine caused a dose-dependent reduction in pulmonary artery pressure in anesthetized Wistar rats with $\mathrm{Su} / \mathrm{Hx}$-induced PH (Iglarz et al., 2015), suggesting that at an earlier 5 -week time point, there is a reactive component of $\mathrm{PH}$ in this rat strain. Whether this reactive component of $\mathrm{PH}$ to vasodilators could still be observed at a later 7-week time point and in the Sprague-Dawley rat model of $\mathrm{Su} / \mathrm{Hx}$ remains to be investigated.

$\mathrm{PH}$ is associated with remodeling of the small pulmonary arteries, vascular cell proliferation, and obliteration of the pulmonary microvasculature (Pietra et al., 1989; Mitani et al., 2001; Budhiraja et al., 2004; Farber and Loscalzo, 2004). Some studies have shown that chronic $\mathrm{Hx}$ is associated with increased proliferation and migration of VSMCs and a synthetic pulmonary VSMC phenotype (Cooper and Beasley, 1999; Schultz et al., 2006; Chen and Khalil, 2008). The "proliferative" or "synthetic" VSMCs lose their ability to contract, partly owing to a lack of contractile proteins such as myosin. Our data support potential VSMC phenotypic switch from a contractile to the synthetic phenotype in $\mathrm{Su} / \mathrm{Hx}$ rats for the following reasons: 1) Both $\mathrm{Phe}$ and $\mathrm{KCl}$ contraction were reduced in the pulmonary artery of $\mathrm{Su} / \mathrm{Hx}$ rats compared with $\mathrm{Nx}, \mathrm{Hx}$, and Su rats; 2) the vasodilator responses of pulmonary artery to both $\mathrm{ACh}$ and $\mathrm{SNP}$ were reduced in $\mathrm{Su} / \mathrm{Hx}$ compared with $\mathrm{Nx}$ and $\mathrm{Hx}$ rats; 3) even after endothelium removal, the $\mathrm{KCl}$ contraction was still reduced in $\mathrm{Su} / \mathrm{Hx}$ compared with $\mathrm{Nx}$ and $\mathrm{Su}$ rats; 4) histologic analysis demonstrated increased thickening of pulmonary arteriolar wall thickening in $\mathrm{Su} / \mathrm{Hx}$ compared with $\mathrm{Nx}$ rats; and 5) contractile markers were reduced in the pulmonary arteries of $\mathrm{Su} / \mathrm{Hx}$ compared with $\mathrm{Nx}$ rats. A prior study showed that the contraction to only one concentration of Phe $\left(10^{-6} \mathrm{M}\right)$ and $\mathrm{KCl}(80 \mathrm{~mm})$ was insignificantly enhanced in pulmonary artery of $\mathrm{Su} / \mathrm{HX}$ model in Fischer 344 rats (Alzoubi et al., 2013). This result differs from the present findings that both $\mathrm{Phe}$ and $\mathrm{KCl}$ contraction were significantly reduced in our $\mathrm{Su} / \mathrm{Hx}$ model. The difference in the results could be related to differences in the rat strain (Sprague-Dawley vs. Fischer 344). Also, the present study examined the full concentration-response curve to Phe rather than the response to only one Phe concentration, thus demonstrating decreased sensitivity particularly to low Phe concentrations in the pulmonary artery of $\mathrm{Su} / \mathrm{Hx}$ rats. Additionally, the present study examined how the contractile response to Phe could be modified by inhibitors of the NO-cGMP relaxation pathway and endothelium removal. Most importantly, the present study showed that the reduced $\mathrm{Phe}$ and $\mathrm{KCl}$ contraction were specific to the pulmonary artery of $\mathrm{Su} / \mathrm{Hx}$ rats and were not observed in the aorta or mesenteric artery. The differences in the findings make it important to study more completely the changes in vascular function in other $\mathrm{Su} / \mathrm{Hx}$ models in future studies. Nevertheless, the present study is the first to describe in a comprehensive manner the full spectrum of vascular dysfunction in $\mathrm{Su} / \mathrm{Hx}$ Sprague-Dawley rats, which extends beyond endothelial 
dysfunction. Our observed decrease in mechanical force to vasoconstrictor stimuli and decreased relaxation to vasodilator stimuli is a novel finding and supports structural remodeling and stiffening of the pulmonary vascular wall. Our findings suggest that, in addition to endothelial dysfunction, there is impaired intrinsic VSMC dysfunction and thus provide a novel target for potential therapies.

One limitation of the present study is that we used extralobar first-branch pulmonary arteries, which may not reflect the entire pulmonary circulation, particularly the intralobar resistance vessels that are thought to play a greater role in the control of pulmonary vascular resistance. Future studies should examine whether the observed reduced contraction/relaxation in extralobar pulmonary arteries also occurs in distal intralobar resistance vessels; however, studies in more proximal vessels are also important for the following reasons: 1) Small intralobular arteries take their vascular feed from the larger extralobar conduit pulmonary arteries, and remodeling of the parent conduit arteries is expected to affect the structural integrity and function of the smaller branches and downstream vessels; 2) thickening of the tunica media occurs at all levels of the arterial tree in the context of pulmonary vascular remodeling (Pugliese et al., 2015); 3) some researchers have reported qualitative similarities (and quantitative difference) in vasoactive responses between main and intralobar pulmonary arteries in the setting of experimental PH (Jeffery and Wanstall, 2001); and 4) functional changes in pulmonary vascular stiffness are increasingly thought to be important in disease progression and were due mainly to decreased compliance of larger vessels (Hunter et al., 2011). Given that there is increasing appreciation of the contribution of proximal vascular stiffness to pulmonary vascular impedance in the setting of $\mathrm{PH}$ (Lammers et al., 2008; Sanz et al., 2009), we believe it is important to examine these responses in addition to the changes in the distal pulmonary circulation in experimental PH. Nevertheless, the vasorelaxation effects may depend not only on the size of the vessel but also on the vasodilator factors involved. Although NO plays a greater role in larger vessels, EDHF is more important in smaller vessels. There is a possibility that a smaller pulmonary artery might show differences in vasorelaxation compared with the first branch, and therefore the vasorelaxation response in smaller branches is important and should be examined in future investigations.

The present study focused on understanding the mechanisms underlying impaired pulmonary vascular contractility in the $\mathrm{Su} / \mathrm{Hx}$ model with the hope that improved understanding of these mechanisms will provide the framework for future intervention studies to evaluate the efficacy of novel agents aiming to restore a contractile pulmonary VSMC phenotype. In this context, we found that endothelium-dependent relaxation was reduced in $\mathrm{Su} / \mathrm{Hx}$ model of $\mathrm{PH}$. Endotheliumderived vasodilators include $\mathrm{NO}, \mathrm{PGI}_{2}$, and EDHF. We observed that ACh-induced relaxation of pulmonary artery was completely abolished by the NOS inhibitor L-NAME and guanylate cyclase inhibitor ODQ, suggesting a major role of NO-cGMP pathway, and likely a minimal role of $\mathrm{PGI}_{2}$ or EDHF. Whereas our studies suggest a relatively small role of endothelium-derived $\mathrm{PGI}_{2}$ in the observed changes in pulmonary artery of $\mathrm{Su} / \mathrm{Hx}$, this does not exclude the possibility of $\mathrm{PGI}_{2}$ release from other vascular cells including VSMCs. Given the favorable vascular effects of $\mathrm{PGI}_{2}$ therapy in the management of $\mathrm{PH}$, future studies should further examine the levels of $\mathrm{PGI}_{2}$ and the blood pressure depressor and vasodilator responsiveness to $\mathrm{PGI}_{2}$ in the $\mathrm{Su} / \mathrm{Hx}$ model of $\mathrm{PH}$.

Perspective. Studies in animal models of $\mathrm{PH}$ provide important information regarding the vascular and molecular mechanisms underlying human $\mathrm{PH}$. The present study demonstrates that severe $\mathrm{PH}$ in the $\mathrm{Su} / \mathrm{Hx}$ model is associated with reduced responsiveness of the pulmonary arterial circulation to both vasoconstrictor and vasodilator stimuli. The specific reduction in the pulmonary vascular responses in the setting of $\mathrm{Su} / \mathrm{Hx}$-induced $\mathrm{PH}$ may be explained by a vascular bed-specific switch of VSMCs from a contractile to a synthetic phenotype, as well as reduction in endothelium-dependent relaxation pathways. Our results may have important clinical implications for $\mathrm{PH}$ as they suggest that therapeutic interventions targeting vasoconstriction may not produce the desired effects unless new approaches to improve the responsiveness of the pulmonary circulation to vasoactive substances are developed.

\section{Acknowledgments}

The authors thank Dr. Xiaoliang Liang for technical assistance.

\section{Authorship Contributions}

Participated in research design: Christou, Hudalla, Michael, Filatava, Khalil.

Conducted experiments: Christou, Hudalla, Michael, Filatava, Li, Zhu, Possomato-Vieira, Dias-Junior.

Performed data analysis: Christou, Hudalla, Michael, Filatava, Li, Zhu, Possomato-Vieira, Dias-Junior, Khalil.

Wrote or contributed to the writing of the manuscript: Christou, Hudalla, Michael, Kourembanas, Khalil.

\section{References}

Abe K, Toba M, Alzoubi A, Ito M, Fagan KA, Cool CD, Voelkel NF, McMurtry IF, and Oka M (2010) Formation of plexiform lesions in experimental severe pulmonary arterial hypertension. Circulation 121:2747-2754.

Adnot S, Raffestin B, Eddahibi S, Braquet P, and Chabrier PE (1991) Loss of endothelium-dependent relaxant activity in the pulmonary circulation of rats exposed to chronic hypoxia. J Clin Invest 87:155-162.

Aiello RJ, Bourassa PA, Zhang Q, Dubins J, Goldberg DR, De Lombaert S, Humbert M, Guignabert C, Cavasin MA, McKinsey TA, et al. (2017) Tryptophan hydroxylase 1 inhibition impacts pulmonary vascular remodeling in two rat models of pulmonary hypertension. J Pharmacol Exp Ther 360:267-279.

Alzoubi A, Almalouf P, Toba M, O'Neill K, Qian X, Francis M, Taylor MS, Alexeyev M, McMurtry IF, Oka M, et al. (2013) TRPC4 inactivation confers a survival benefit in severe pulmonary arterial hypertension. Am J Pathol 183:1779-1788.

Ambalavanan N, Bulger A, Murphy-Ullrich J, Oparil S, and Chen YF (2005) Endothelin-A receptor blockade prevents and partially reverses neonatal hypoxic pulmonary vascular remodeling. Pediatr Res 57:631-636.

Arciniegas E, Frid MG, Douglas IS, and Stenmark KR (2007) Perspectives on endothelial-to-mesenchymal transition: potential contribution to vascular remodeling in chronic pulmonary hypertension. Am J Physiol Lung Cell Mol Physiol 293: L1-L8.

Bonnet S, Rochefort G, Sutendra G, Archer SL, Haromy A, Webster L, Hashimoto K, Bonnet SN, and Michelakis ED (2007) The nuclear factor of activated T cells in pulmonary arterial hypertension can be therapeutically targeted. Proc Natl Acad Sci USA 104:11418-11423.

Budhiraja R, Tuder RM, and Hassoun PM (2004) Endothelial dysfunction in pulmonary hypertension. Circulation 109:159-165.

Burger CD (2009) Pulmonary hypertension in COPD: a review and consideration of the role of arterial vasodilators. COPD 6:137-144.

Busse R and Fleming I (1999) Nitric oxide, nitric oxide synthase, and hypertensive vascular disease. Curr Hypertens Rep 1:88-95.

Chen W and Khalil RA (2008) Differential [Ca2+]i signaling of vasoconstriction in mesenteric microvessels of normal and reduced uterine perfusion pregnant rats. Am J Physiol Regul Integr Comp Physiol 295:R1962-R1972.

Christou H, Morita T, Hsieh CM, Koike H, Arkonac B, Perrella MA, and Kourembanas S (2000) Prevention of hypoxia-induced pulmonary hypertension by enhancement of endogenous heme oxygenase-1 in the rat. Circ Res 86: 1224-1229.

Christou H, Reslan OM, Mam V, Tanbe AF, Vitali SH, Touma M, Arons E, Mitsialis SA, Kourembanas S, and Khalil RA (2012) Improved pulmonary vascular reactivity and decreased hypertrophic remodeling during nonhypercapnic acidosis in experimental pulmonary hypertension. Am J Physiol Lung Cell Mol Physiol 302:L875-L890. 
Cooper AL and Beasley D (1999) Hypoxia stimulates proliferation and interleukin1alpha production in human vascular smooth muscle cells. Am J Physiol 277: H1326-H1337.

Crews JK, Herrington JN, Granger JP, and Khalil RA (2000) Decreased endothelium-dependent vascular relaxation during reduction of uterine perfusion pressure in pregnant rat. Hypertension 35:367-372.

Dallas A and Khalil RA (2003) Ca2+ antagonist-insensitive coronary smooth muscle contraction involves activation of epsilon-protein kinase C-dependent pathway. Am J Physiol Cell Physiol 285:C1454-C1463.

de Raaf MA, Schalij I, Gomez-Arroyo J, Rol N, Happé C, de Man FS, VonkNoordegraaf A, Westerhof N, Voelkel NF, and Bogaard HJ (2014) SuHx rat model: partly reversible pulmonary hypertension and progressive intima obstruction. Eur Respir J 44:160-168.

Fagan KA, Oka M, Bauer NR, Gebb SA, Ivy DD, Morris KG, and McMurtry IF (2004) Attenuation of acute hypoxic pulmonary vasoconstriction and hypoxic pulmonary hypertension in mice by inhibition of Rho-kinase. Am J Physiol Lung Cell Mol Physiol 287:L656-L664.

Farber HW and Loscalzo J (2004) Pulmonary arterial hypertension. N Engl J Med 351:1655-1665.

Félétou M and Vanhoutte PM (2006) Endothelium-derived hyperpolarizing factor: where are we now? Arterioscler Thromb Vasc Biol 26:1215-1225.

Fullerton DA, Hahn AR, and McIntyre RC, Jr (1996) Mechanistic imbalance of pulmonary vasomotor control in progressive lung injury. Surgery 119:98-103.

Geraci MW, Gao B, Shepherd DC, Moore MD, Westcott JY, Fagan KA, Alger LA, Tuder RM, and Voelkel NF (1999) Pulmonary prostacyclin synthase overexpression in transgenic mice protects against development of hypoxic pulmonary hypertension. J Clin Invest 103:1509-1515.

Gillespie MN, Olson JW, Reinsel CN, O'Connor WN, and Altiere RJ (1986) Vascular hyperresponsiveness in perfused lungs from monocrotaline-treated rats. $A m J$ Physiol 251:H109-H114.

Homma N, Nagaoka T, Morio Y, Ota H, Gebb SA, Karoor V, McMurtry IF, and Oka M (2007) Endothelin-1 and serotonin are involved in activation of RhoA/Rho kinase signaling in the chronically hypoxic hypertensive rat pulmonary circulation. $J$ Cardiovasc Pharmacol 50:697-702.

Hoshikawa Y, Nana-Sinkam P, Moore MD, Sotto-Santiago S, Phang T, Keith RL, Morris KG, Kondo T, Tuder RM, Voelkel NF, et al. (2003) Hypoxia induces different genes in the lungs of rats compared with mice. Physiol Genomics 12 209-219.

Hoshikawa Y, Voelkel NF, Gesell TL, Moore MD, Morris KG, Alger LA, Narumiya S, and Geraci MW (2001) Prostacyclin receptor-dependent modulation of pulmonary vascular remodeling. Am J Respir Crit Care Med 164:314-318.

Hunter KS, Lammers SR, and Shandas R (2011) Pulmonary vascular stiffness: measurement, modeling, and implications in normal and hypertensive pulmonary circulations. Compr Physiol 1:1413-1435.

Iglarz M, Landskroner K, Bauer Y, Vercauteren M, Rey M, Renault B, Studer R, Vezzali E, Freti D, Hadana H, et al. (2015) Comparison of macitentan and bosentan on right ventricular remodeling in a rat model of non-vasoreactive pulmonary hypertension. J Cardiovasc Pharmacol 66:457-467.

Itoh H, Yokochi A, Yamauchi-Kohno R, and Maruyama K (1999) Effects of the endothelin ET(A) receptor antagonist, TA-0201, on pulmonary arteries isolated from hypoxic rats. Eur $J$ Pharmacol 376:233-238.

Ivy DD, Yanagisawa M, Gariepy CE, Gebb SA, Colvin KL, and McMurtry IF (2002) Exaggerated hypoxic pulmonary hypertension in endothelin B receptor-deficient rats. Am J Physiol Lung Cell Mol Physiol 282:L703-L712.

Jeffery TK and Wanstall JC (2001) Comparison of pulmonary vascular function and structure in early and established hypoxic pulmonary hypertension in rats. Can $J$ Physiol Pharmacol 79:227-237.

Jiang B, Deng Y, Suen C, Taha M, Chaudhary KR, Courtman DW, and Stewart DJ (2016) Marked strain-specific differences in the SU5416 rat model of severe pulmonary arterial hypertension. Am J Respir Cell Mol Biol 54:461-468.

Lammers SR, Kao PH, Qi HJ, Hunter K, Lanning C, Albietz J, Hofmeister S, Mecham R, Stenmark KR, and Shandas R (2008) Changes in the structure-function relationship of elastin and its impact on the proximal pulmonary arterial mechanics of hypertensive calves. Am J Physiol Heart Circ Physiol 295 H1451-H1459.

Leblais V, Pourageaud F, Ivorra MD, Guibert C, Marthan R, and Muller B (2004) Role of alpha-adrenergic receptors in the effect of the beta-adrenergic receptor ligands, CGP 12177, bupranolol, and SR 59230A, on the contraction of rat intrapulmonary artery. J Pharmacol Exp Ther 309:137-145.

Lee JE, Hillier SC, and Knoderer CA (2008) Use of sildenafil to facilitate weaning from inhaled nitric oxide in children with pulmonary hypertension following surgery for congenital heart disease. J Intensive Care Med 23:329-334.

Li X, Zhang X, Leathers R, Makino A, Huang C, Parsa P, Macias J, Yuan JX, Jamieson SW, and Thistlethwaite PA (2009) Notch3 signaling promotes the development of pulmonary arterial hypertension. Nat Med 15:1289-1297.

Lincoln TM, Cornwell TL, and Taylor AE (1990) cGMP-dependent protein kinase mediates the reduction of $\mathrm{Ca} 2+$ by cAMP in vascular smooth muscle cells. Am J Physiol 258:C399-C407.

Majed BH and Khalil RA (2012) Molecular mechanisms regulating the vascular prostacyclin pathways and their adaptation during pregnancy and in the newborn. Pharmacol Rev 64:540-582.

Majka SM, Skokan M, Wheeler L, Harral J, Gladson S, Burnham E, Loyd JE, Stenmark KR, Varella-Garcia M, and West J (2008) Evidence for cell fusion is absent in vascular lesions associated with pulmonary arterial hypertension. Am $J$ Physiol Lung Cell Mol Physiol 295:L1028-L1039.

Mam V, Tanbe AF, Vitali SH, Arons E, Christou HA, and Khalil RA (2010) Impaired vasoconstriction and nitric oxide-mediated relaxation in pulmonary arteries of hypoxia- and monocrotaline-induced pulmonary hypertensive rats. $J$ Pharmacol Exp Ther 332:455-462.
Mazzuca MQ, Li W, Reslan OM, Yu P, Mata KM, and Khalil RA (2014) Downregulation of microvascular endothelial type $\mathrm{B}$ endothelin receptor is a centra vascular mechanism in hypertensive pregnancy. Hypertension 64:632-643.

Mazzuca MQ, Mata KM, Li W, Rangan SS, and Khalil RA (2015) Estrogen receptor subtypes mediate distinct microvascular dilation and reduction in $[\mathrm{Ca} 2+] \mathrm{I}$ in mesenteric microvessels of female rat. $J$ Pharmacol Exp Ther 352:291-304.

McMurtry MS, Archer SL, Altieri DC, Bonnet S, Haromy A, Harry G, Bonnet S, Puttagunta L, and Michelakis ED (2005) Gene therapy targeting survivin selectively induces pulmonary vascular apoptosis and reverses pulmonary arterial hypertension. J Clin Invest 115:1479-1491.

McMurtry MS, Bonnet S, Wu X, Dyck JR, Haromy A, Hashimoto K, and Michelakis ED (2004) Dichloroacetate prevents and reverses pulmonary hypertension by inducing pulmonary artery smooth muscle cell apoptosis. Circ Res 95:830-840.

Michelakis ED, McMurtry MS, Wu XC, Dyck JR, Moudgil R, Hopkins TA, Lopaschuk GD, Puttagunta L, Waite R, and Archer SL (2002) Dichloroacetate, a metabolic modulator, prevents and reverses chronic hypoxic pulmonary hypertension in rats: role of increased expression and activity of voltage-gated potassium channels. Circulation 105: 244-250.

Mitani Y, Ueda M, Komatsu R, Maruyama K, Nagai R, Matsumura M, and Sakurai M (2001) Vascular smooth muscle cell phenotypes in primary pulmonary hypertension. Eur Respir J 17:316-320.

Murphy JG, Fleming JB, Cockrell KL, Granger JP, and Khalil RA (2001) [Ca(2+)](i) signaling in renal arterial smooth muscle cells of pregnant rat is enhanced during inhibition of NOS. Am J Physiol Regul Integr Comp Physiol 280:R87-R99.

Murphy JG and Khalil RA (2000) Gender-specific reduction in contractility and $[\mathrm{Ca}(2+)](\mathrm{i})$ in vascular smooth muscle cells of female rat. Am J Physiol Cell Physiol 278:C834-C844

Nozik-Grayck E and Stenmark KR (2007) Role of reactive oxygen species in chronic hypoxia-induced pulmonary hypertension and vascular remodeling. Adv Exp Med Biol 618:101-112.

O'Farrell AM, Yuen HA, Smolich B, Hannah AL, Louie SG, Hong W, Stopeck AT, Silverman LR, Lancet JE, Karp JE, et al. (2004) Effects of SU5416, a small molecule tyrosine kinase receptor inhibitor, on FLT3 expression and phosphorylation in patients with refractory acute myeloid leukemia. Leuk Res 28:679-689.

Oka M, Fagan KA, Jones PL, and McMurtry IF (2008) Therapeutic potential of RhoA/Rho kinase inhibitors in pulmonary hypertension. $\mathrm{Br} J$ Pharmacol 155 : 444-454.

Oka M, Homma N, Taraseviciene-Stewart L, Morris KG, Kraskauskas D, Burns N, Voelkel NF, and McMurtry IF (2007) Rho kinase-mediated vasoconstriction is important in severe occlusive pulmonary arterial hypertension in rats. Circ Res 100:923-929.

Parkington HC, Coleman HA, and Tare M (2004) Prostacyclin and endotheliumdependent hyperpolarization. Pharmacol Res 49:509-514.

Pietra GG, Edwards WD, Kay JM, Rich S, Kernis J, Schloo B, Ayres SM, Bergofsky EH, Brundage BH, Detre KM, et al. (1989) Histopathology of primary pulmonary hypertension. A qualitative and quantitative study of pulmonary blood vessels from 58 patients in the National Heart, Lung, and Blood Institute, Primary Pulmonary Hypertension Registry. Circulation 80:1198-1206.

Pugliese SC, Poth JM, Fini MA, Olschewski A, El Kasmi KC, and Stenmark KR (2015) The role of inflammation in hypoxic pulmonary hypertension: from cellular mechanisms to clinical phenotypes. Am J Physiol Lung Cell Mol Physiol $\mathbf{3 0 8}$ L229-L252.

Ringvold HC and Khalil RA (2017) Protein kinase C as regulator of vascular smooth muscle function and potential target in vascular disorders. Adv Pharmacol 78 203-301.

Salamanca DA and Khalil RA (2005) Protein kinase C isoforms as specific targets for modulation of vascular smooth muscle function in hypertension. Biochem Pharmacol 70:1537-1547.

Sanz J, Kariisa M, Dellegrottaglie S, Prat-González S, Garcia MJ, Fuster V, and Rajagopalan S (2009) Evaluation of pulmonary artery stiffness in pulmonary hypertension with cardiac magnetic resonance. JACC Cardiovasc Imaging 2:286-295.

Schermuly RT, Dony E, Ghofrani HA, Pullamsetti S, Savai R, Roth M, Sydykov A, Lai YJ, Weissmann N, Seeger W, et al. (2005) Reversal of experimental pulmonary hypertension by PDGF inhibition. J Clin Invest 115:2811-2821.

Schermuly RT, Kreisselmeier KP, Ghofrani HA, Yilmaz H, Butrous G, Ermert L, Ermert M, Weissmann N, Rose F, Guenther A, et al. (2004) Chronic sildenafil treatment inhibits monocrotaline-induced pulmonary hypertension in rats. Am J Respir Crit Care Med 169:39-45.

Schultz K, Fanburg BL, and Beasley D (2006) Hypoxia and hypoxia-inducible factor1alpha promote growth factor-induced proliferation of human vascular smooth muscle cells. Am J Physiol Heart Circ Physiol 290:H2528-H2534.

Shimoda LA, Sham JS, Shimoda TH, and Sylvester JT (2000a) L-type $\mathrm{Ca}(2+)$ channels, resting $[\mathrm{Ca}(2+)](\mathrm{i})$, and ET-1-induced responses in chronically hypoxic pulmonary myocytes. Am J Physiol Lung Cell Mol Physiol 279:L884-L894.

Shimoda LA, Sham JS, and Sylvester JT (2000b) Altered pulmonary vasoreactivity in the chronically hypoxic lung. Physiol Res 49:549-560.

Stehlik J and Movsesian MA (2009) Combined use of PDE5 inhibitors and nitrates in the treatment of pulmonary arterial hypertension in patients with heart failure. $J$ Card Fail 15:31-34.

Stenmark KR, Meyrick B, Galie N, Mooi WJ, and McMurtry IF (2009) Animal models of pulmonary arterial hypertension: the hope for etiological discovery and pharmacological cure. Am J Physiol Lung Cell Mol Physiol 297:L1013-L1032.

Taraseviciene-Stewart L, Kasahara Y, Alger L, Hirth P, Mc Mahon G, Waltenberger J, Voelkel NF, and Tuder RM (2001) Inhibition of the VEGF receptor 2 combined with chronic hypoxia causes cell death-dependent pulmonary endothelial cell proliferation and severe pulmonary hypertension. FASEB $J$ 15:427-438.

Tonelli AR, Alnuaimat H, and Mubarak K (2010) Pulmonary vasodilator testing and use of calcium channel blockers in pulmonary arterial hypertension. Respir Med 104:481-496. 
Weigand L, Shimoda LA, and Sylvester JT (2011) Enhancement of myofilament calcium sensitivity by acute hypoxia in rat distal pulmonary arteries. Am J Physio Lung Cell Mol Physiol 301:L380-L387.

Xiao Y, Christou H, Liu L, Visner G, Mitsialis SA, Kourembanas S, and Liu H (2013) Endothelial indoleamine 2,3-dioxygenase protects against development of pulmonary hypertension. Am J Respir Crit Care Med 188:482-491.

Yin N, Kaestle S, Yin J, Hentschel T, Pries AR, Kuppe H, and Kuebler WM (2009) Inhaled nitric oxide versus aerosolized iloprost for the treatment of pulmonary hypertension with left heart disease. Crit Care Med 37:980-986.
Zhou C, Townsley MI, Alexeyev M, Voelkel NF, and Stevens T (2016) Endothelial hyperpermeability in severe pulmonary arterial hypertension: role of storeoperated calcium entry. Am J Physiol Lung Cell Mol Physiol 311:L560-L569.

Address correspondence to: Dr. Raouf A Khalil, Harvard Medical School, Brigham and Women's Hospital, Division of Vascular Surgery, 75 Francis Street, Boston, MA 02115. E-mail: raouf_khalil@hms.harvard.edu 